\title{
Performance of laterally loaded piles considering soil and interface parameters
}

\author{
Behzad Fatahi ${ }^{* 1}$, Sudip Basack ${ }^{2 a}$, Patrick Ryan ${ }^{1 b}$, \\ Wan-Huan Zhou ${ }^{3 \mathrm{C}}$ and Hadi Khabbaz ${ }^{1 \mathrm{~d}}$ \\ ${ }^{1}$ School of Civil and Environmental Engineering, University of Technology Sydney (UTS), Sydney, Australia \\ ${ }^{2}$ School of Civil, Mining and Environmental Engineering, University of Wollongong, \\ New South Wales, Australia \\ ${ }^{3}$ Department of Civil and Environmental Engineering, University of Macau, Macau, China
}

(Received March 24, 2014, Revised May 30, 2014, Accepted July 11, 2014)

\begin{abstract}
To investigate the soil-pile interactive performance under lateral loads, a set of laboratory model tests was conducted on remoulded test bed of soft clay and medium dense sand. Then, a simplified boundary element analysis had been carried out assuming floating pile. In case of soft clay, it has been observed that lateral loads on piles can initiate the formation of a gap, soil heave and the tension crack in the vicinity of the soil surface and the interface, whereas in medium dense sand, a semi-elliptical depression zone can develop. Comparison of test and boundary element results indicates the accuracy of the solution developed. However, in the boundary element analysis, the possible shear stresses likely to be developed at the interface are ignored in order to simplify the existing complex equations. Moreover, it is unable to capture the influence of base restraint in case of a socketed pile. To bridge up this gap and to study the influence of the initial stress state and interface parameters, a field based case-study of laterally-loaded pile in layered soil with socketed tip is explored and modelled using the finite element method. The results of the model have been verified against known field measurements from a case-study. Parametric studies have been conducted to investigate the influence of the coefficient of lateral earth pressure and the interface strength reduction factor on the results of the model.
\end{abstract}

Keywords: single pile; boundary element; finite element; soil-pile interface

\section{Introduction}

Structures subject to lateral loads rely on pile foundations for stability. Such lateral loadings may include wind loads, earthquake loads, wave loads and inclined loads (Fan and Long 2005, Tabatabaiefar et al. $2013 \mathrm{a}, \mathrm{b}$ ). Lateral loads may also occur in the form of impact loads, such as from a ship collision with a bridge pier (Reese and Van Impe 2011). Due to the prevalence of such

*Corresponding author, Senior Lecturer of Geotechnical Engineering, Ph.D., M.Eng, B.Eng, CPEng, NPER, E-mail: behzad.fatahi@uts.edu.au

${ }^{a}$ Research Associate, Ph.D., MC.Eng, B.Eng

${ }^{\mathrm{b}}$ Research Assistant, B.Eng

${ }^{\mathrm{c}}$ Assistant Professor of Geotechnical Engineering, Ph.D., M.Eng, B.Eng

${ }^{\mathrm{d}}$ Associate Professor of Geotechnical Engineering, Ph.D., M.Eng, B.Eng 
lateral loadings, structures such as high-rise buildings, long-span bridges (Kim et al. 2011) and offshore structures (Matlock 1970) require pile foundation design that involves careful consideration and analysis of laterally loaded pile behaviour.

The lateral capacity of a single pile may be limited by the shearing capacity of surrounding soil, or by the structural capacity of the pile itself, or by excessive lateral deformation. There are different design procedures depending on the types of soil, the modes of failure of the pile, and the rigidity of the pile cap. In classical geotechnical engineering design, if the rotation at the head of a pile is not constrained, the pile is called a "free-head" pile. In contrast if the rotation at the head is constrained by the pile cap, the pile is called a "fixed-head" pile. Methods of calculating the lateral capacities of free head and fixed head single piles under different failure modes were proposed by Broms (1964a, b) and expanded by Poulos and Davis (1980). As shown in Fig. 1, for a laterally loaded single pile, failure may occur either by a lateral bearing failure of the soil (mode 1) or by development of a plastic hinge in the pile (mode 2). The third mode of failure may only occur for fixed head piles where two plastic hinges are developed in the pile. Free head short piles tend to fail by a rigid movement (fixed head) or by rotation around a point near their toe (free head), while structural failure of long piles forms a hinge at a point below the ground level (mode 2) and sometimes in another point just under the pile cap (mode 3 for fixed head piles). The dominant mode of failure depends on the soil stiffness and strength, pile stiffness and strength, pile length, and the moment and horizontal load applied at the pile head. It is difficult to establish a relationship between all the above parameters and the dominant mode of failure, to be able to calculate the horizontal capacity of the pile based on the dominant mode. According to Poulos and Davis (1980), a practical method of calculating the horizontal capacity of a pile is to analyse all conditions of failure and select the lower lateral load capacity calculated based on all failure modes.

The analysis methodologies of laterally-loaded pile behaviour has evolved over time - from the empirical and limit state methods (Broms 1964a) through to $p-y$ (load-transfer) methods (Matlock 1970, Reese et al. 1975, Hokmabadi et al. 2012) through to finite element or difference methods (Yang and Jeremic 2002, Fan and Long 2005, Lebeau 2008, Ahmadi and Ahmari 2009, Kim et al. 2011, Sawant and Shukla 2012, Chore et al. 2012, Hokmabadi et al. 2014a, b), analytical methods (Ashour and Norris 2003, Duncan et al. 2005, Levy et al. 2007, Hajialilue-Bonab et al. 2011,

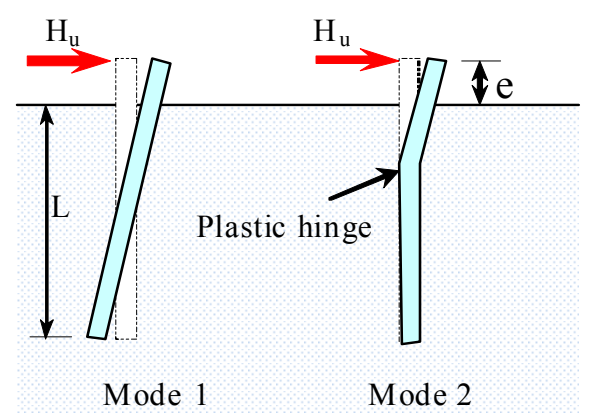

(a)

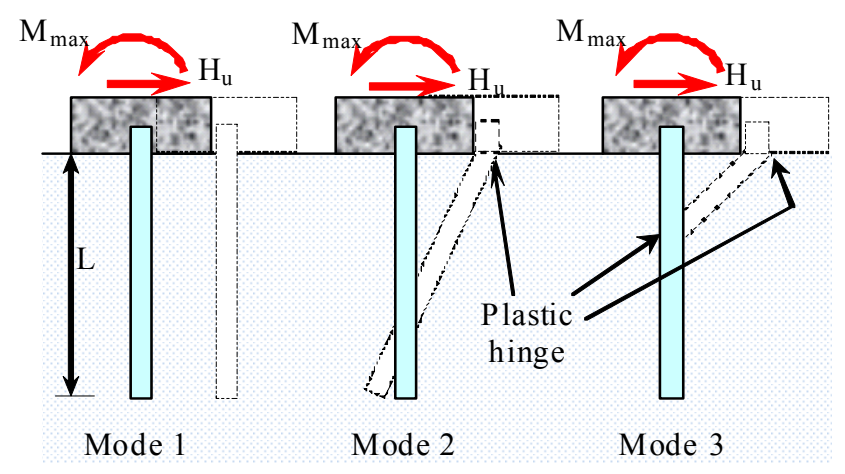

(b)

Fig. 1 Modes of failures for plies under lateral loads: (a) free head piles (b) fixed head (modified after Poulos and Davis, 1980) 
2013, Higgins et al. 2013), reliability analysis (Chan and Low 2009) and cyclic lateral loading (Li et al. 2010).

Poulos (1971a, b) proposed a simplified boundary element model (BEM) to predict the response of a laterally loaded single pile and a pile group. While the pile displacements were computed from bending moment equations, the Mindlin's method was employed to evaluate the soil displacements. The formulations developed were utilized (Poulos and Davis 1980) to obtain a series of design curves. In spite of the versatility of the model, it has the inherent difficulty of the assumption that the soil behaves as a purely elastic material. In the $p-y$ curve method proposed by Reese (1977), on the other hand, the lateral soil pressure and the corresponding displacement of the interface at a particular depth were correlated by semi-empirical relations. This method was further improved by Allotey and El Naggar (2008).

This study focuses on effects of the initial (or in-situ) stress state and interface parameters on the performance of a laterally loaded single pile. Commencing from a laboratory based model study on a fixed headed pile embedded in the remoulded beds of soft clay and medium dense sand followed by the boundary element modelling (BEM), further detailed analysis was carried out on the effects of interface parameters in more complex subsoil condition by employing a finite element-based parametric study embracing the coefficient of lateral earth pressure at rest $\left(K_{0}\right)$ and the interface strength reduction factor $\left(R_{\text {inter }}\right)$. Literature review (e.g., Brown and Shie 1991, Dodds and Martin 2007, Lebeau 2008) confirms that there has been limited prior investigations associated with the effects of such parameters on the finite element-based models.

The main aim of this study is investigating effects of different model parameters on the performance of the laterally loaded piles while adopting simplified or rigorous numerical modelling. A simplified boundary element method (BEM) has been adopted to investigate the effects of soil stiffness on pile head displacement, and the soil reaction. Experimental results were essential to validate the results of the simplified boundary element solution. However, in the BEM analysis, the possible shear stresses likely to be developed at the interface are ignored in order to simplify the already complex equations. In addition, the developed BEM methodology cannot conveniently be applied to reasonably predict the pile-soil interactive performance under lateral loading in some complex situations, for example when the pile is embedded in a multi-layer subsoil system and socketed at its tip. Thus, to investigate importance of soil interface parameter as well as the initial stress state of the soil, more rigorous analysis is required. In this study, three-dimensional finite element method (FEM) has been adopted to investigate effects of soil-pile interface reduction factor as well as the coefficient of lateral earth pressure on the performance of laterally loaded piles. The adopted finite element solution has been verified against the field measurements.

\section{Experimental and simplified numerical investigations}

To study the pile-soil interactive performance under lateral loads, a set of laboratory model tests with steel pipe piles embedded in uniform soil beds was performed. This was followed by the theoretical analysis using a simplified boundary element modelling. The investigations performed and the relevant observations made are sequentially described in this section.

\subsection{Laboratory model tests}

A new experimental set up equipped with motor-gear, shaft and worm gear mechanism was 


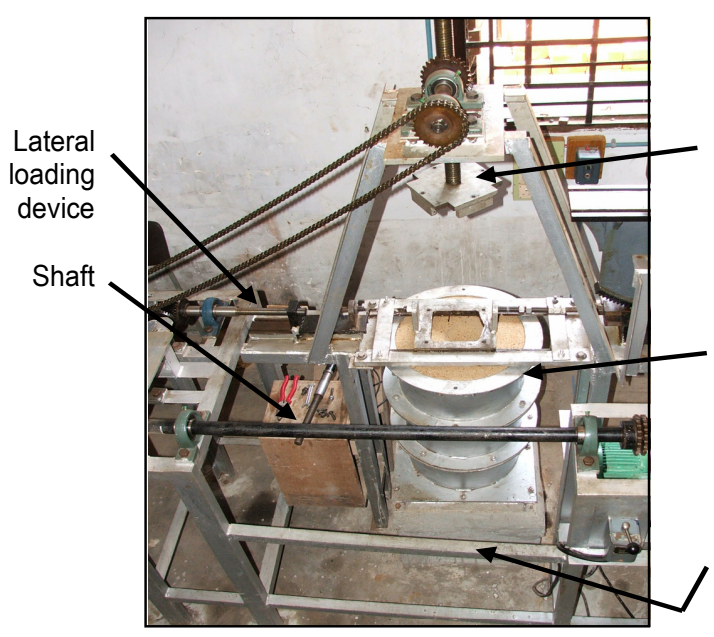

(a)

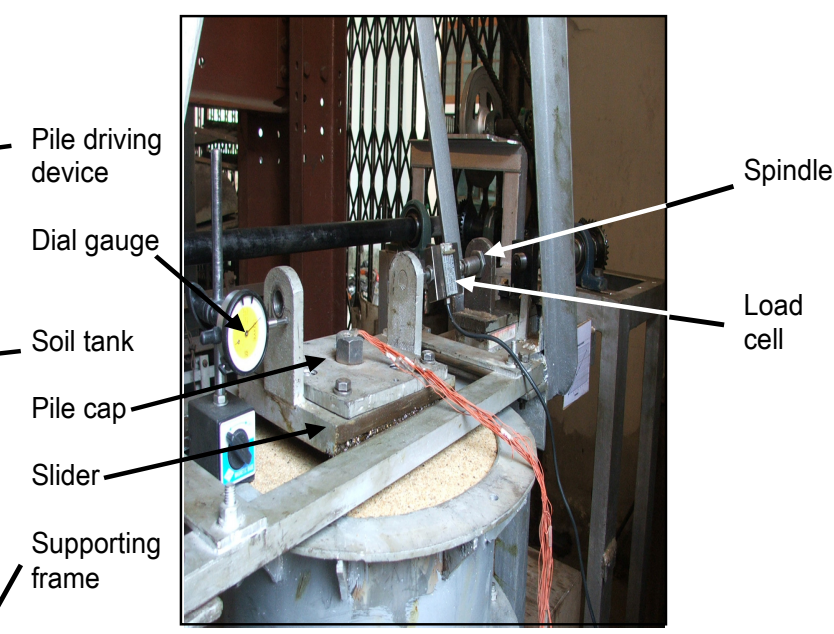

(b)

Fig. 2 Photographic views of the experimental set up: (a) overall view; (b) close view of loading device

used to impart lateral static loading on model piles under displacement controlled mode (Fig. 2). The stainless steel model pipe piles having external diameter of $25 \mathrm{~mm}$ and wall thickness of 3 $\mathrm{mm}$ were driven through the remoulded test bed prepared in a cylindrical soil tank $(400 \mathrm{~mm}$ diameter $\times 650 \mathrm{~mm}$ height) with a depth of embedment of $500 \mathrm{~mm}(L / d=20)$. The piles were bolted at the top with a square steel plate (pile cap), which was firmly attached to a sliding plate such a way to simulate the fixed pile head condition. The loading spindle was connected to the sliding plate through load cell in a manner that the lateral load was applied on the pile head at an effective height of $90 \mathrm{~mm}$ above the soil surface. The rotation of the motor induces a steady horizontal advancement of the pile cap @ $1 \mathrm{~mm} /$ minute. The pile head deflection was measured by a dial gauge having at least a count of $0.01 \mathrm{~mm}$. More details of the set up can be found in Basack (2009).

Experiments were conducted separately with single pile in soft clay and medium dense sand. Locally available kaolin powder was intimately mixed with water (moisture content $=45 \%$ ) to prepare the reconstituted soft clay bed. Hydrometer test indicated that clay size particles $(<2 \mu \mathrm{m})$ accounted for about $60 \%$ of the specimen while the particles smaller than silt size $(2-60 \mu \mathrm{m})$ accounted for about $40 \%$ of the specimen. The liquid limit and the plastic limit were obtained as $52 \%$ and $30 \%$, respectively $(\mathrm{PI}=22 \%$ ). In the test tank, the soil-water mixture was placed and compacted in layers by a special rammer $(50 \mathrm{~N}$ weight $\times 60 \mathrm{~mm}$ freefall height $)$. The average shear strength parameters obtained from UU triaxial test of few samples taken from the reconstituted test bed were: $c_{u}=5 \mathrm{kPa}$ and $\phi=0$. In case of medium dense sand bed, the soil tank was filled with dry sand (particle size $0.2-0.5 \mathrm{~mm}, C_{u}=6.5, C_{c}=1.5$ ) by rainfall technique from a uniform height of $2 \mathrm{~m}$. The dry density of sand bed was measured as $\gamma=20 \mathrm{kN} / \mathrm{m}^{3}$ with a relative density of $D_{r}=64 \%$. By direct shear test, the friction angle was found as $\phi=32^{\circ}$.

The tests were performed in undrained condition. During lateral loading in progress, a soil heave at the front of pile and a gap at the back were visualized in the vicinity of the soil surface in case of the uniform soft clay bed, when the measured pile head deflection attained about $5 \%$ of pile diameter (Fig. 3(a)). Tension cracks were observed to initiate on the soil surface from about 


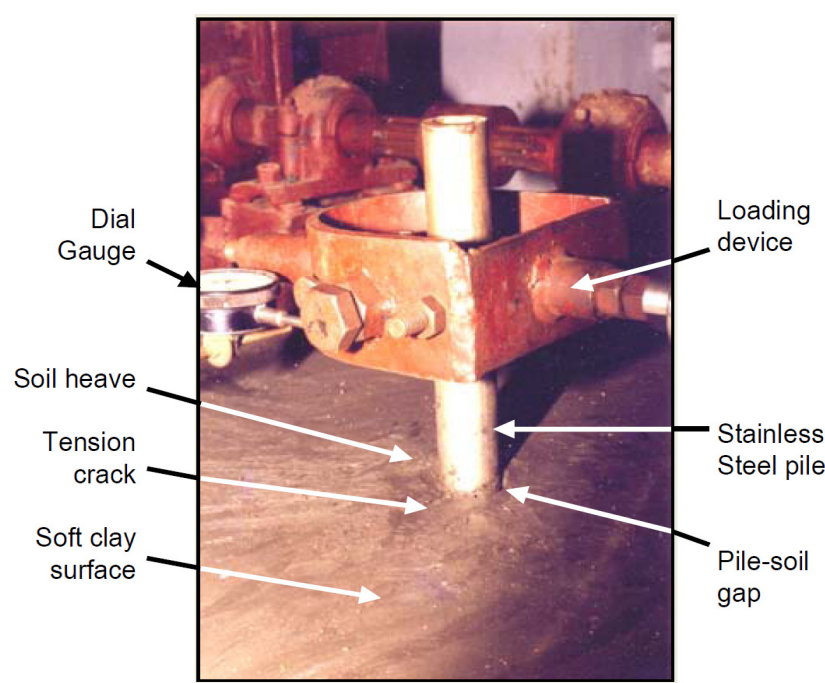

(a)

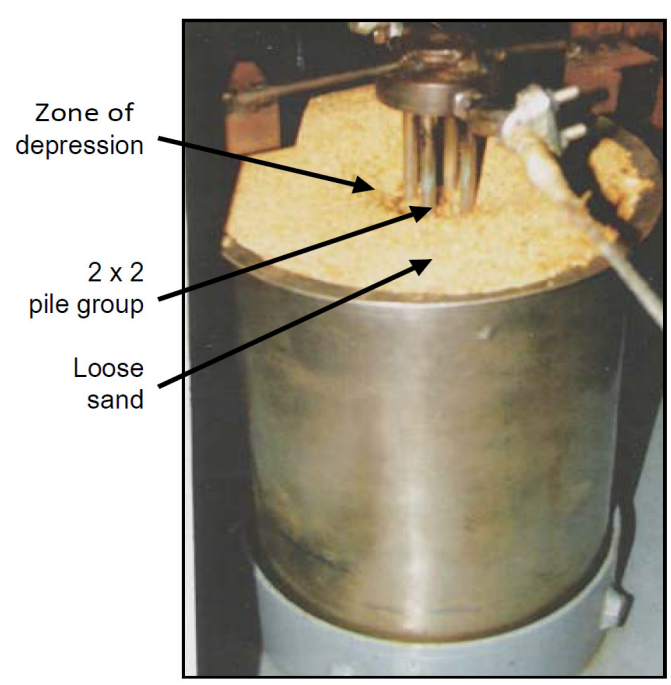

(b)

Fig. 3 Close view of lateral load test for: (a) single pile in soft clay. (b) pile group in layered soil

$10 \%$ normalized pile head deflection. In case of medium dense sand, a soil heave and a semi-elliptical zone of depression were observed progressively developing on the ground surface in the front and at the back of the pile group (Fig. 3(b)).

The Authors agree that preparation of a perfectly uniform test bed of clay in the laboratory should be done by remoulding the clay-water mixture at moisture content slightly higher to the liquid limit and then consolidating it to the desired state (Som 1993, Al-Mhaidib 2006a, 2007), although the water content is progressively reduced due to consolidation. The other alternative is to fill up and compact the test tank in layers with the clay water mixture (Narasimha Rao and Prasad 1993, Basack 2010, Chandrasekaran et al. 2010). It has been observed that the variation of the strength and stiffness of the remoulded test bed in the latter method is insignificant. To simulate the field condition relevant to offshore, the test bed was remoulded near to the liquid limit. This factor, in addition to the absence of adequate surcharge facility for consolidation, has attributed to the choice of the latter method for preparing the test bed.

In laboratory pile load tests, the presence of the rigid boundary of the test tank is likely to influence the experimental results. The zone in which the soil will be affected is influenced by soil density and pile installation method is reported to be in the range of 3 to 8 times the pile diameter (Meyerhof 1959, Robinsky and Morrison 1964, Turner and Kulhawy 1987, Al-Mhaidib 2006b). In the present investigation, the tank diameter is 16 times the pile diameter and the base is situated at a distance of 6 times the pile diameter below the tip which minimise the boundary effect on the test results.

It is worth mentioning that the ideal instrument for conducting model tests of laterally loaded pile is the geotechnical centrifuge where the package of soil, the model and other equipments are spin about a fixed axis and the radial acceleration so produced is several times the gravitational acceleration ' $g$ ' (Dyson 1999). However, in absence of such facilities in the laboratory, the model tests in the acceleration field of $1 \mathrm{~g}$ were conducted by many researchers (Meyerhof and Adams 1968, Narasimha Rao et al. 1993). The scaling laws for model testing have been covered in details 
by Schofield (1980) and Taylor (1995). It has been observed by Oveseen (1979) that the deviation in behavioural pattern of model and prototype foundations is not significant when the ratio does not exceed 1:15. However, for model tests carried out in $1 \mathrm{~g}$ acceleration field, it is most convenient to non-dimensionalize the experimental parameters in form so as to avoid the scaling effects (Basack 2010). This principle is followed in this paper.

\subsection{Simplified boundary element modelling}

To investigate the effects of lateral loading on the single, vertical, fixed headed floating pile, a simplified boundary element model (BEM) has been developed. While the detailed description of the model has been published elsewhere (Basack and Dey 2012), few important illustrations has been included in this paper, for example: the details of the matrices involved, and boundary conditions applied, etc.

The method proposed by Poulos (1971a) was followed as a preliminary guideline with necessary modifications in accordance with the relevance of the present problem. The elastic pile was assumed to be embedded in homogeneous, isotropic, semi-infinite and elastic-perfectly plastic subsoil having a constant Young's modulus $\left(E_{s}\right)$ and Poisson's ratio $\left(\mu_{\mathrm{s}}\right)$, which remain unaffected by the presence of the pile. The possible horizontal shear stresses that may be developed at the interface are ignored. The pile was idealized as a thin vertical plate having its diameter $d$, embedded length $L$ and flexural rigidity $E_{p} I_{p}$, subjected to a lateral static load $H$ applied at a height of $e$ above the ground surface. The embedded portion of the pile has been longitudinally discretised into $n+1$ elements (Fig. 4), $n$ being a positive integer greater than unity.

Each of these pile elements were assumed to be subjected to a uniform lateral soil pressure. The soil displacements at the nodal points were obtained from the correlations of Douglas and Davis (1964) obtained by integration of Mindlin (1936) equation, whereas the nodal pile deflections are evaluated from the flexure equation of elastic beam. From the displacement compatibility, the soil

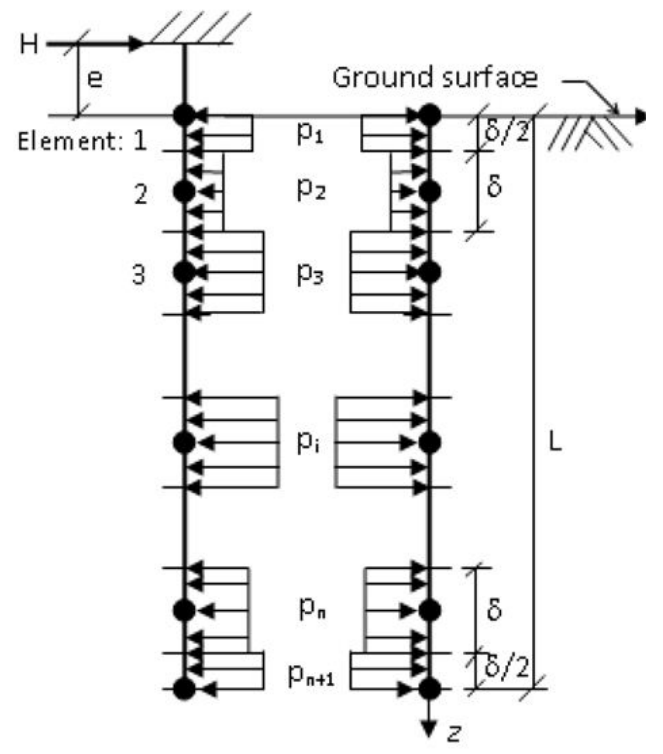

Fig. 4 Boundary element discretization: (a) idealised pile; and (b) interface pressure on soil 
and pile nodal displacements are equated. Eliminating these displacements and applying the appropriate boundary conditions at the pile tip, equilibrium conditions and the deflection expressions of the portion of pile above the ground surface, the unknown soil pressures were obtained by solving the following matrix equation

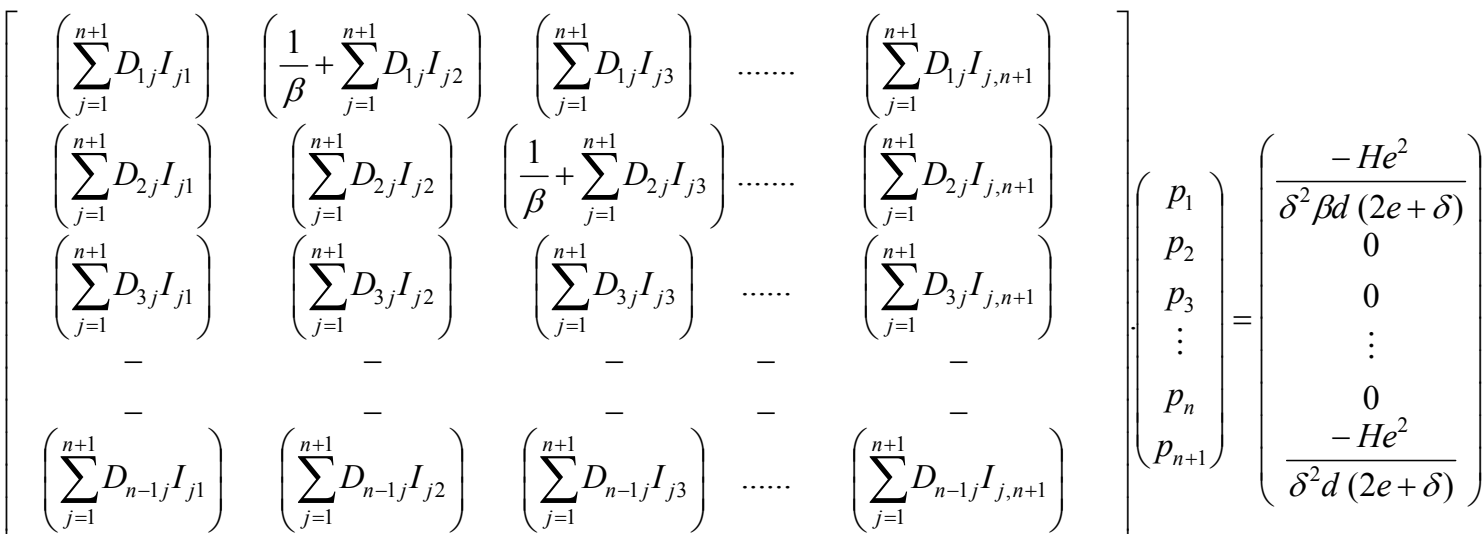

$$
\begin{aligned}
& \begin{array}{lllll}
F_{1} & F_{2} & F_{3} & \ldots \ldots & F_{n+1}
\end{array} \\
& \left.\left(Q_{1}-\omega I_{11}+\omega I_{21}\right)\left(Q_{2}-\omega I_{12}+\omega I_{22}\right)\left(Q_{3}-\omega I_{13}+\omega I_{23}\right) \ldots \ldots\left(Q_{n+1}-\omega I_{1, n+1}+\omega I_{2, n+1}\right)\right]
\end{aligned}
$$

where, $I_{i j}=$ soil displacement influence factor for the displacement at $i^{\text {th }}$ element due to lateral soil pressure $p_{j}$ acting of the $j^{\text {th }}$ element; $D_{i j}=$ is the element at the $i^{\text {th }}$ row and $j^{\text {th }}$ column of the coefficient matrix obtained from the flexure equation of the pile; $\beta=E_{p} I_{p} /\left(\delta^{4} d\right) ; \omega=2 \beta \delta /(2 e+\delta)$; $\delta=L / n ; F_{j}=1$ for $2 \leq j \leq n$ and $F_{1}=F_{n+1}=0.5 ; Q_{j}=(j-1)$ for $2 \leq j \leq n$ and $Q_{1}=0.125, Q_{n+1}=$ $0.5 n-0.125$.

The solution to Eq. (1) provides the initial elastic values of the unknown pressures $p_{j}$. Incorporating local yield of soil, these solutions were recycled until nowhere on the interface, the lateral soil pressure exceeded the corresponding yield pressure of the soil. As recommended by Jamiolkowski and Garassino (1977), these yield values were taken as $2 c_{u}$ at the ground surface and increasing linearly to a limiting value of $9 c_{u}$ at a depth of $3 d$ and beyond. For sand, on the other hand, the yield soil pressures were chosen as $m$ times of the Rankine's passive earth pressure, where, the factor $m$ varies between 3 to 5 (Poulos 1988). The conservative analysis of Broms (1964a) suggested the value of $m$ as 3, although a value of 5 may be close to reality (Poulos 1988). The yield pressure of sandy soil was considered proportional to the passive earth pressure coefficient of soil, thus essentially increases linearly with depth and confining pressure.

Because of a limited ability of soil to take tension, a pile-soil gap is likely to be developed in the vicinity of the ground surface especially for cohesive soil. Although such separation induces an increase in the pile displacements (Douglas and Davis 1964), in most practical cases, this increase is about $30-40 \%$ for a relatively flexible pile (Poulos and Davis 1980). For cohesionless soil, the same does not significantly affect the pile-soil response. Therefore, for clay, the above analysis was modified to account for pile-soil gap by increasing the values of $I_{i j}$ for the relevant pile elements by a factor of 2 (Poulos and Davis 1980) and further recycling the solution.

Once the unknown lateral soil pressures are determined incorporating soil yield and pile-soil separation, the nodal pile deflections $\rho_{i}$ are evaluated using the flexure equations of the elastic pile. The pile head deflection $\rho_{h}$ are found considering the elastic condition of the portion of pile above the ground surface. The nodal bending moments, computed considering the equilibrium of the pile 
portion below the node, are given by

$$
M_{j}=-\left[\frac{\delta d}{8} p_{j}+\frac{\delta d}{2}\left(L-(j-1) \delta-\frac{\delta}{4}\right) p_{n+1}+\delta^{2} d \sum_{k=j+1}^{n}(k-j) p_{k}\right]
$$

The computed results using this model were observed to be highly sensitive to the strength and stiffness parameters of the soil.

\subsection{Analysis and Interpretation}

In case of laboratory model test, it is quite difficult to collect undisturbed sample to reasonably estimate the soil stiffness. The most satisfactory means of determining the Young's modulus of soil is to conduct lateral pile tests and to back-figure the modulus by fitting the observations to the theory (Poulos and Davis 1980, Poulos 1988). In the present work, the experimentally obtained lateral load-displacement results have been essentially compared with previously published empirical correlations and the boundary element solutions (Fig. 5). For soft clay, different values of $E_{s} / c_{u}$ for the soft clay varying from 250 to 400 (Poulos 1973, Jamiolkowski and Garassino 1977) have been adopted. In case of sand, the values of $m$ are taken as 5 and 3 with the non-dimensionalized Young's modulus of soil $\left[E_{s} /\left(K_{p} \gamma D\right)\right]$ chosen as 5000, 4000, 3500 and 3000. The Poisson's ratio of clay and sand were taken as 0.5 and 0.3 , respectively.

For pile in soft clay, it has been observed from Fig. 5(a) that the higher the magnitude of $E_{s} / c_{u}$ chosen, the lesser was the computed pile head deflections due to increased relative pile-soil stiffness. In the range of $0<\rho_{h} / d \leq 10 \%$, the computed load-deflections curves corresponding to $E_{s} / c_{u}$ taken as 350 and 400 are observed to be in close agreement with the model test results, whereas for $\rho_{h} / d>10 \%$, the computed curve relevant to $E_{s} / c_{u}=250$ are in reasonable proximity with the experimental curves.

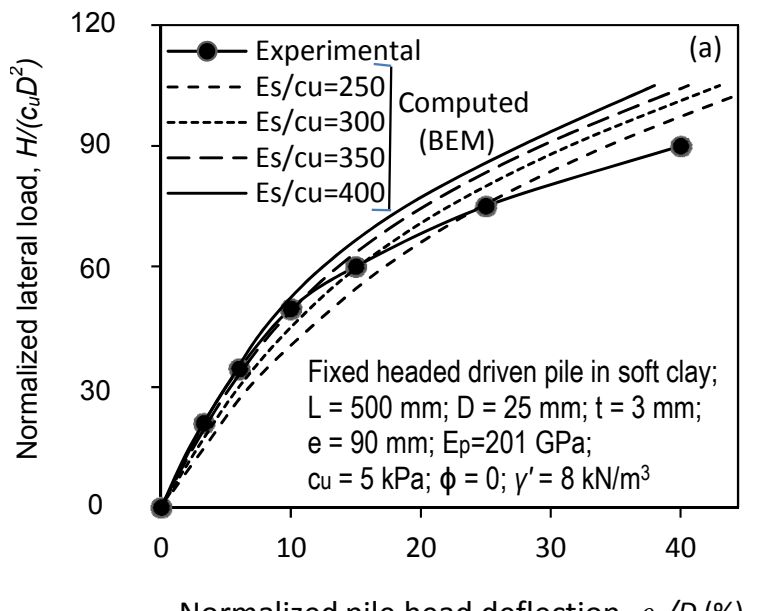

(a)

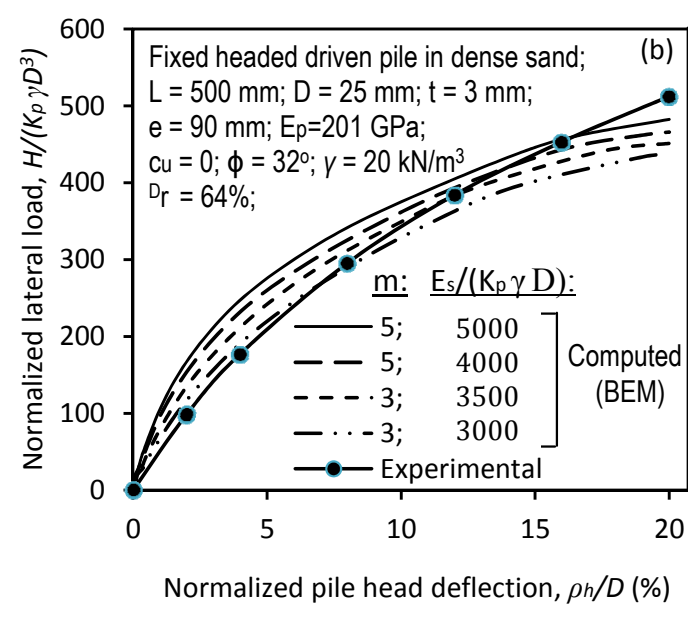

(b)

Fig. 5 Comparison of measured load-deflection response with BEM simulated results for: (a) uniform soft clay; (b) medium dense sand 
In case of pile in medium dense sand, the computed load-deflection curves for the chosen values of $m$ and $E_{s} /\left(K_{p} \gamma D\right)$ were observed to be in agreement with the two experimental curves. For $0<\rho_{h} / d \leq 8 \%$, the numerical curve corresponding to $m=3$ and $E_{s} /\left(K_{p} \gamma D\right)=3000$ was found close to the experimental values, whereas in case of $12 \% \leq \rho_{h} / d \leq 15 \%$, the numerical curve for $m$ $=5$ and $E_{s} /\left(K_{p} \gamma D\right)=4000$ was close enough to the test results.

From the BEM computation, the profiles for lateral soil pressure on pile (Fig. 6) and bending moments (Fig. 7) were simulated for both soft clay and medium dense sand. The values of the computed soil pressure and the bending moment were normalized as $p / c_{u}$ and $M /\left(c_{u} D^{3}\right)$ for clay and $p /\left(K_{p} \gamma D\right)$ and $M /\left(K_{p} \gamma D^{4}\right)$ for sand respectively, $p$ and $M$ being the lateral soil pressure and the pile bending moment respectively. The lateral soil pressure was observed to increase with depth till the attainment of peak value and thereafter decreased following a curvilinear pattern. Near the pile tip, the lateral soil pressure was observed to be negative (i.e., directed towards $H$ ) possibly due to reverse pile displacement near the tip (see Fig. 1). The influence of the variation of soil modulus

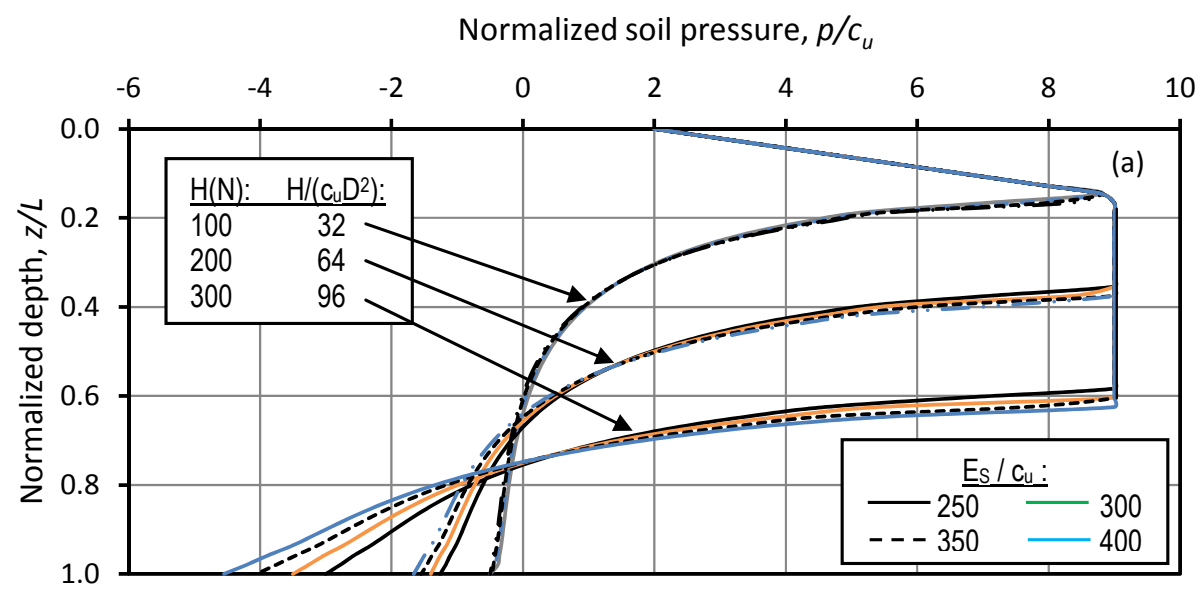

(a)

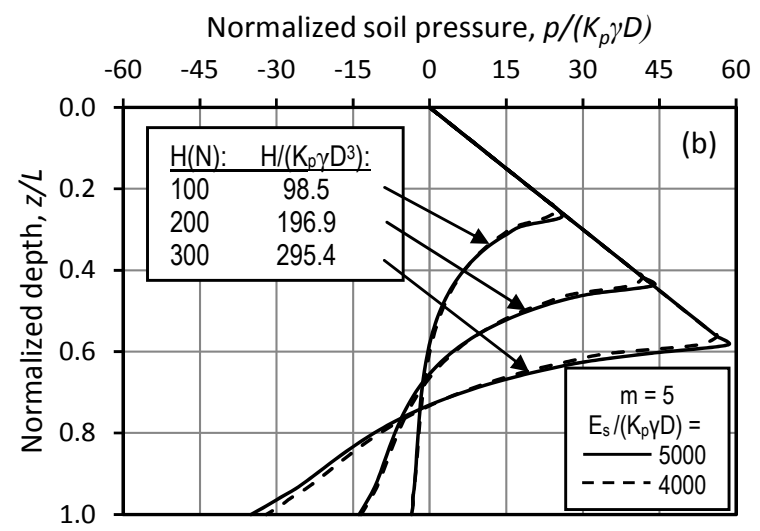

(b)

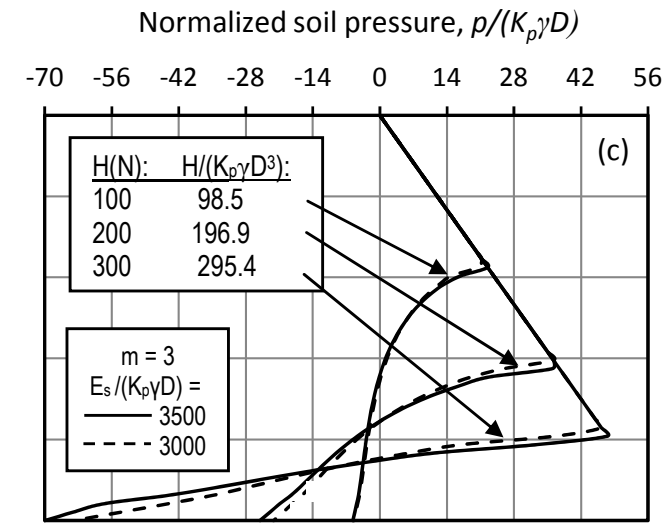

(c)

Fig. 6 BEM simulated lateral soil pressure on pile surface for: (a) uniform soft clay; (b) medium dense sand $[m=5]$; (c) medium dense sand $[m=3]$ 
[ $E_{s} / c_{u}$ for clay and $E_{s} /\left(K_{p} \gamma D\right)$ for sand] was observed to be increasingly significant with depth and load level. In case of uniform soft clay, the normalized depth $(z / L)$ of zero soil pressure was found to vary from 0.60 to 0.75 for the load range of $32 \leq H /\left(c_{u} D^{2}\right) \leq 96$ (see Fig. 6(a)). For medium dense sand, on the other hand, the normalized depth $z / L$ relevant to the peak value and zero soil pressure for the load range of $98.5 \leq H /\left(K_{p} \gamma D^{3}\right) \leq 295.4$ was found to occur at $0.27-0.57$ and $0.60-0.73$ for $m=5$ and $E_{s} /\left(K_{p} \gamma D\right)=5000$ and 4000 (see Fig. 6(b)) and 0.37-0.78 and 0.62-0.86 for $m=3$ and $E_{s} /\left(K_{p} \gamma D\right)=3500$ and 3000 (see Fig. 6(c)) respectively.

As initially suggested by Broms (1964a, b) and further modified by Poulos and Davis (1980), the failure modes are different for short and long piles (see Fig. 1). In case of short piles, failure occurs due to lateral yielding of surrounding soil, whereas failure of long piles are accompanied by yielding of the pile material itself prior to soil yield (Basack 1999). However, irrespective of embedded length and relative flexural stiffness, all laterally loaded piles behave as an elastic beam under working loads (Poulos 1988). In the BEM simulated analysis carried out in the paper, the bending moment of the piles are studied under working loads which are reasonably lower than the yield loads.

The Young's modulus of soil produced a pronounced influence on the magnitude of the BEM simulated bending moment profiles in case of both clay and sand for higher value of applied lateral loads $(H=200 \mathrm{~N}$ and $300 \mathrm{~N})$, while the same is insignificant for the lower load $(H=100 \mathrm{~N})$. Due to rotational restraint, the bending moment was observed to be maximum in magnitude at the pile head. With increasing depth, the bending moment increases following a curvilinear pattern, passes through the point of contra-flexure, attains a maximum positive value and thereafter decreases with depth to zero at the pile base. In case of clay, the normalized depths for contra-flexure and maximum positive bending moments were found to vary in the ranges of 0.1-0.6 and 0.25-0.7 respectively for the applied lateral load ranging as $32 \leq H /\left(c_{u} D^{2}\right) \leq 96$ (see Fig. 7(a)), as against the corresponding depths of 0.38-0.40 and 0.55-0.58 for $m=5$ and $E_{s} /\left(K_{p} \gamma D\right)=5000$ and 4000 (see Fig. 7(b)) and 0.08-0.09 and 0.30-0.35 for $m=3$ and $E_{s} /\left(K_{p} \gamma D\right)=3500$ and 3000 (see Fig. 7(c)) respectively relevant to the load range of $98.5 \leq H /\left(K_{p} \gamma D^{3}\right) \leq 295.4$ for medium dense sand.

\section{Finite element analysis}

The finite element modelling adopted in this study has been carried out on a selected laterally loaded steel pile in Incheon Bridge site located in South Korea, adjacent to Incheon International Airport. There have been numerous experimental and numerical studies performed focusing on behaviour of laterally loaded piles at Incheon Bridge site (e.g., Kim and Jeong 2011, Kim et al. 2011, 2009). Steel pile LTP-1 with the most comprehensive field measurement results has been selected in this study for the numerical simulation. The properties of this steel pile are summarised in Table 1.

Test pile LTP-1 was driven to a depth of $26.6 \mathrm{~m}$ beneath the ground surface, leaving $1 \mathrm{~m}$ of the pile standing, free-headed, above the ground surface. Lateral loads were applied to the pile at a point $0.5 \mathrm{~m}$ below the top of the pile $(e=0.5 \mathrm{~m})$. Loads were imposed using a loading instrument that was fixed to a reaction pile. These loads consisted of seven load increments, ending with what was perceived to be the anticipated design load (approximately $800 \mathrm{kN}$ ). Strain gauges and inclinometers, placed at the top of the pile, at the ground surface, and then every $2 \mathrm{~m}$ below to a depth of $20 \mathrm{~m}$, were used to monitor response of the pile subjected to the lateral loading. Further information on pile setup in details can be found in Kim et al. (2011). 


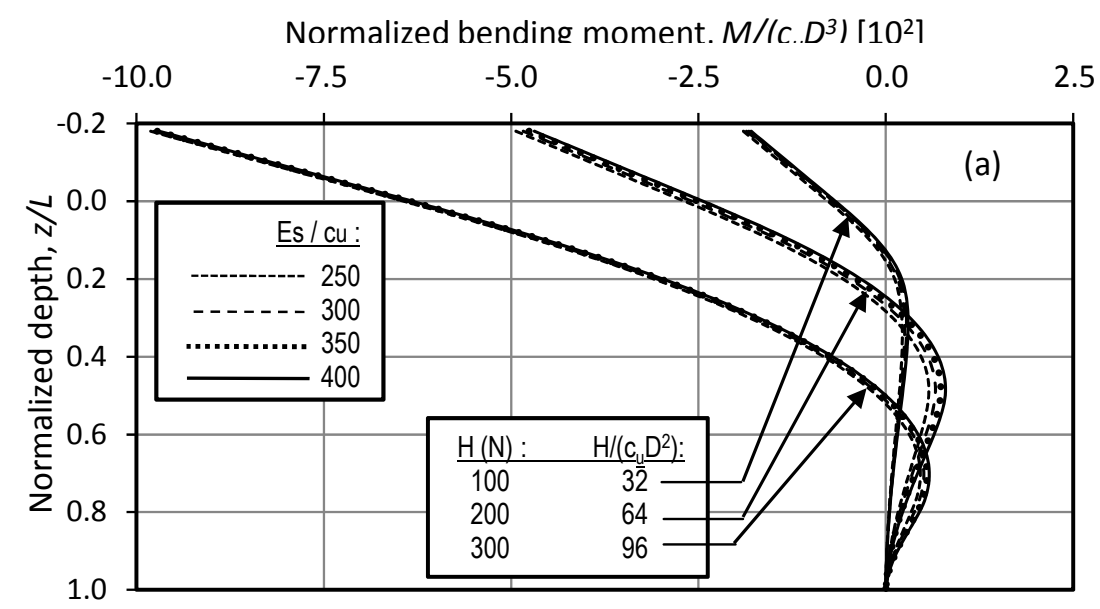

(a)

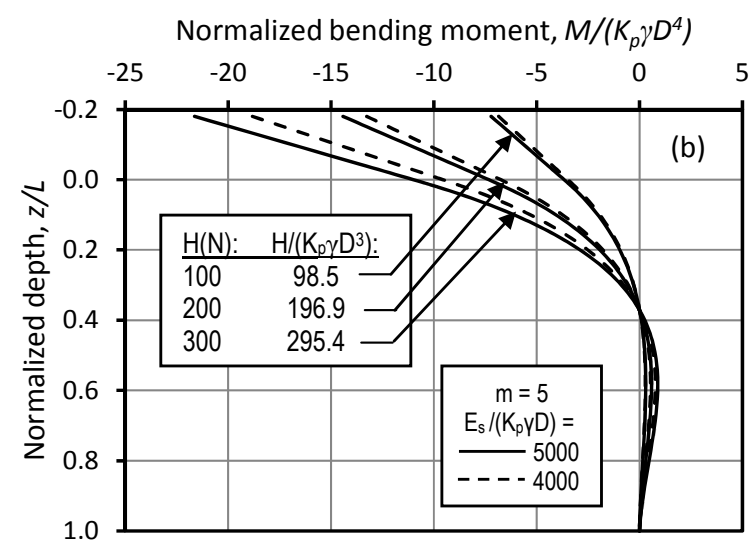

(b)

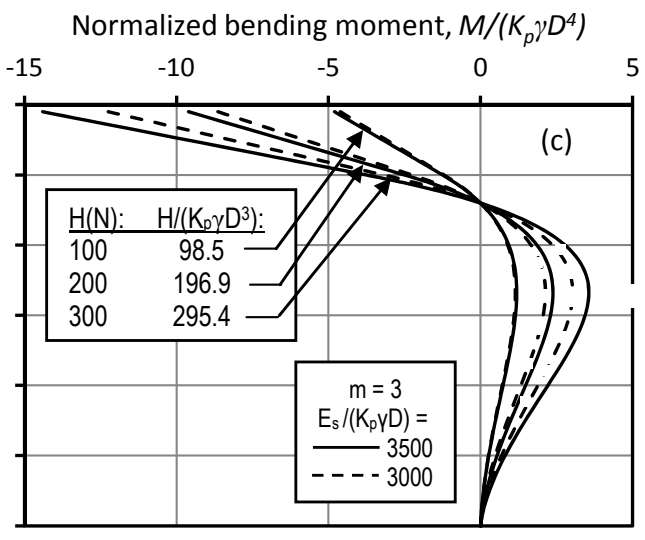

(c)

Fig. 7 BEM simulated pile bending moment profiles for: (a) uniform soft clay; (b) medium dense sand $[m=5]$; (c) medium dense sand $[m=3]$

Table 1 Pile properties for steel pile LTP-1 (adopted from Kim and Jeong, 2011)

\begin{tabular}{cc}
\hline \hline Steel pile properties & Value \\
\hline Diameter $(\mathrm{m})$ & 1.02 \\
Thickness $(\mathrm{m})$ & 0.016 \\
Pile depth $(\mathrm{m})$ & 26.6 \\
Unit weight $(\gamma)\left(\mathrm{kN} / \mathrm{m}^{3}\right)$ & 72 \\
Young's modulus $\left(E_{p}\right)(\mathrm{GPa})$ & 200 \\
Moment of inertia $\left(I_{p}\right)\left(\mathrm{m}^{4}\right)$ & 0.0063 \\
\hline
\end{tabular}


The LTP-1 pile system has been simulated using PLAXIS (2007) 3D Foundation Version 2. For the purposes of this study, a finite element model is created and then parametric analyses are conducted through the implementation of systematic variations of the coefficient of lateral earth pressure at rest $\left(K_{0}\right)$ and the interface strength reduction factor $\left(R_{\text {inter }}\right)$. The adopted numerical model is a real 3D simulation with 3 degrees of freedom and 6 stress and strain components. It is possible to model non-axisymmetric structures such as laterally loaded piles. The numerical modelling involved a central pile and a surrounding soil area in the shape of a regular dodecagon. For the finite element model, the diameter of the steel pile was $1.02 \mathrm{~m}$ (as per the measurements in the field testing) and the distance from the outer edge of the pile to the vertices of the dodecagon was equal to 15 times the pile diameter (Fig. 8). These dimensions were considered to be sufficient

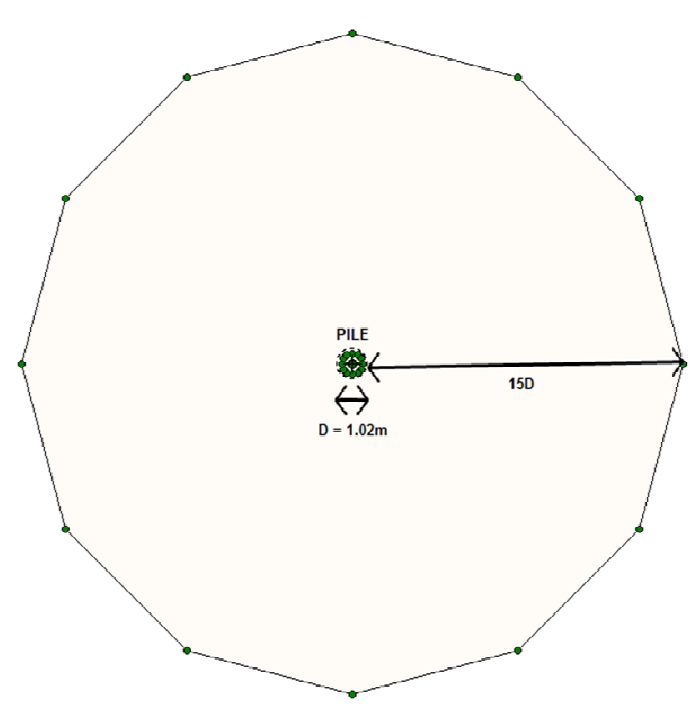

Fig. 8 Boundaries of the finite element model

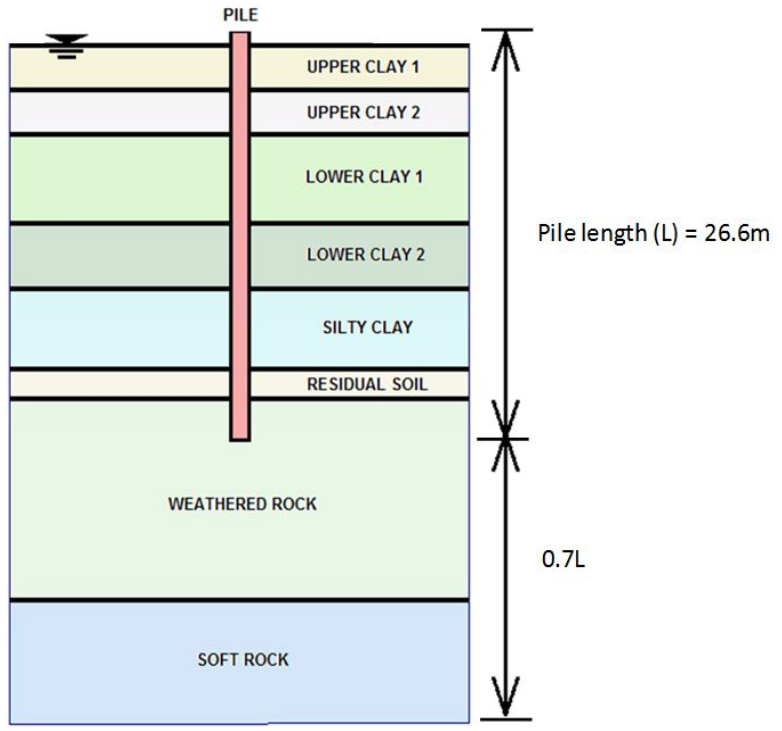

Fig. 9 Soil profile in the vicinity of pile LTP-1

Table 2 Material properties adopted in the numerical model (modified after Kim et al. 2011, Kim and Jeong 2011)

\begin{tabular}{ccccccccccc}
\hline \hline Material & Depth $(\mathrm{m})$ & $\gamma_{\text {sat }}\left(\mathrm{kN} / \mathrm{m}^{3}\right)$ & $N$ value & $v$ & $E_{s}(\mathrm{MPa})$ & $C_{u}(\mathrm{kPa})$ & $\phi\left(^{\circ}\right)$ & $\mathrm{PI}$ & Model \\
\hline Upper clay 1 & $0-3.0$ & 17.5 & $1-3$ & 0.5 & 3 & 15 & 0 & $25-30$ & $\mathrm{MC}$ \\
Upper clay 2 & $3.0-6.3$ & 17.5 & $1-3$ & 0.5 & 10 & 20 & 0 & $25-30$ & $\mathrm{MC}$ \\
Lower clay 1 & $6.3-12.0$ & 17.5 & $4-7$ & 0.5 & 15 & 30 & 0 & $30-35$ & $\mathrm{MC}$ \\
Lower clay 2 & $12.0-16.5$ & 17.5 & $4-7$ & 0.5 & 25 & 50 & 0 & $30-35$ & $\mathrm{MC}$ \\
Silty clay & $16.5-22.0$ & 17.8 & $12-19$ & 0.5 & 27 & 60 & 0 & $35-40$ & $\mathrm{MC}$ \\
Residual soil & $22.0-24.0$ & 17.8 & 44 & 0.5 & 35 & 0 & 34 & - & MC \\
Weathered rock & $24.0-37.5$ & 20.2 & 50 & 0.25 & 110 & - & - & - & Linear-Elastic \\
Soft rock & $37.5-45.9$ & 20.5 & 50 & 0.25 & 200 & - & - & - & Linear-Elastic \\
\hline
\end{tabular}

*Note: $\gamma_{s a t}$ is the saturated unit weight; $v$ is the Poisson's ratio; $E_{s}$ is the Young's modulus; $C_{u}$ is the undrained shear strength; $\phi$ is the friction angle; $N$ is SPT value; PI is the plasticity Index 


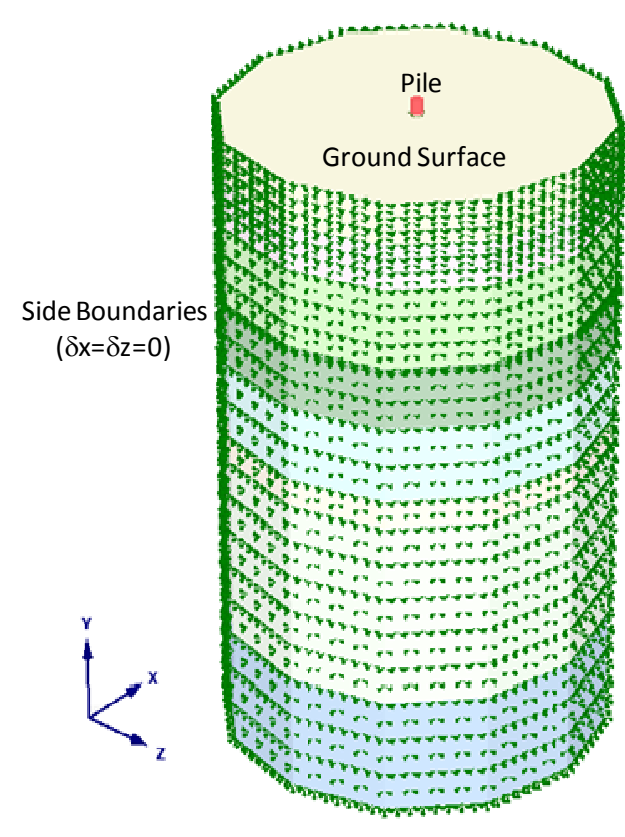

(a)

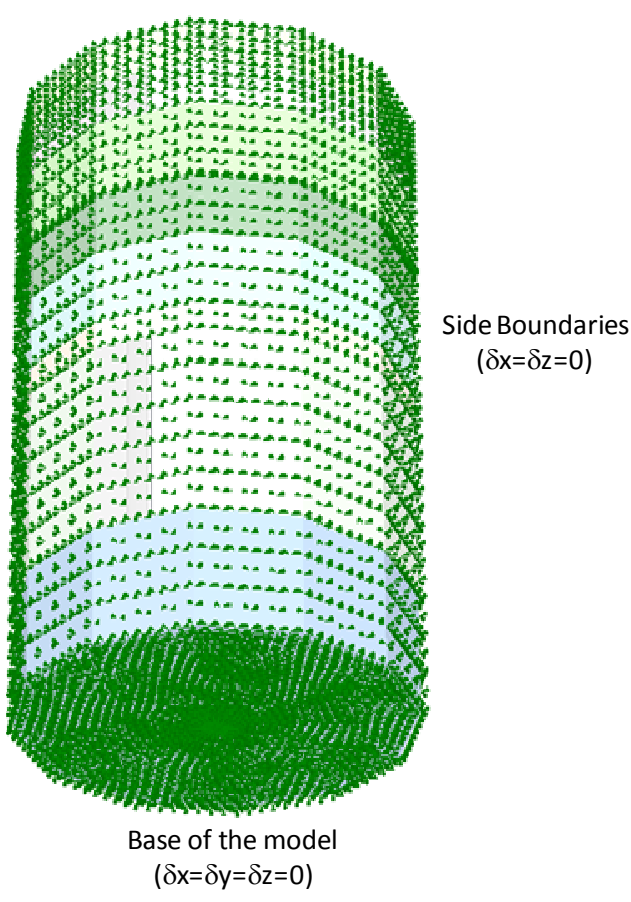

(b)

Fig. 10 Boundary conditions for the finite element model: (a) top view; and (b) bottom view

to nullify the influence of the boundaries (Voottipruex et al. 2011, Kim et al. 2011).

Horizontal soil layers were defined according to the soil profile for pile LTP-1 reported by Kim et al. (2011) and Kim and Jeong (2011). The model was extended to a vertical dimension of 1.7 times the length of the pile to eliminate any boundary effect interference. The water table is located at the ground surface and the subsurface profile has been illustrated in Fig. 9. Modelling was carried out using total stress parameters for undrained conditions during loading for clayey layers adopting Mohr-Coulomb (MC) elastic-perfectly plastic constitutive model with the dilatancy angle equal to zero. The material properties used in the modelling are summarised in Table 2.

As illustrated in Fig. 10, boundary fixities were located along every vertical face and the bottom of the model. The bottom boundary is fixed against movements in all directions, whereas the ground surface is free to move in all directions. The vertical boundaries are fixed against movements in the direction normal to them. A solid pile is used in the numerical model with the flexural rigidity $\left(E_{p} I_{p}\right)$ as the test pile. The flexural rigidity $\left(E_{p} I_{p}\right)$ of the hollow steel pile was calculated using: $E_{p}=2.0 \times 10^{8} \mathrm{MPa}$ and $I_{p}=\pi\left(R^{4}-r^{4}\right) / 4$, where $R$ is the radius of the outer edge of the hollow pile $(0.51 \mathrm{~m})$ and $\mathrm{r}$ is the radius to inner edge of the hollow pile $(0.49 \mathrm{~m})$. In this numerical simulation, the solid pile was modelled as a PLAXIS volume pile and comprised of 12 sectors and soil-pile interface elements, as shown in Figs. 11 and 12.

For models requiring analysis of soil-pile interaction, interface elements are required at the junction of the soil and the structure. Interface elements are assigned a virtual thickness and have strength properties that are linked to those of surrounding soil layers. Interface elements are 


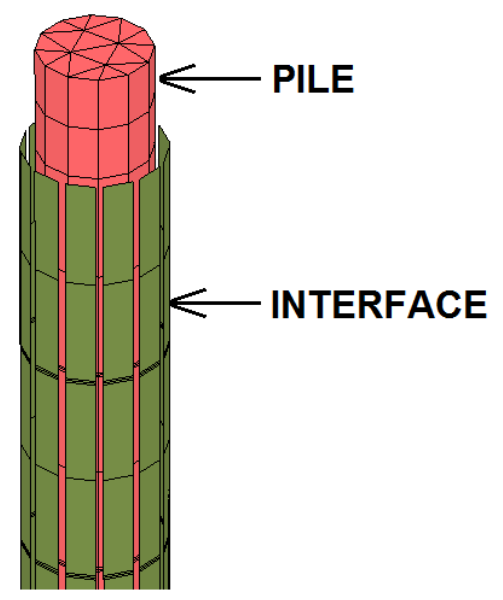

Fig. 11 Interface arrangement around the pile in the finite element model

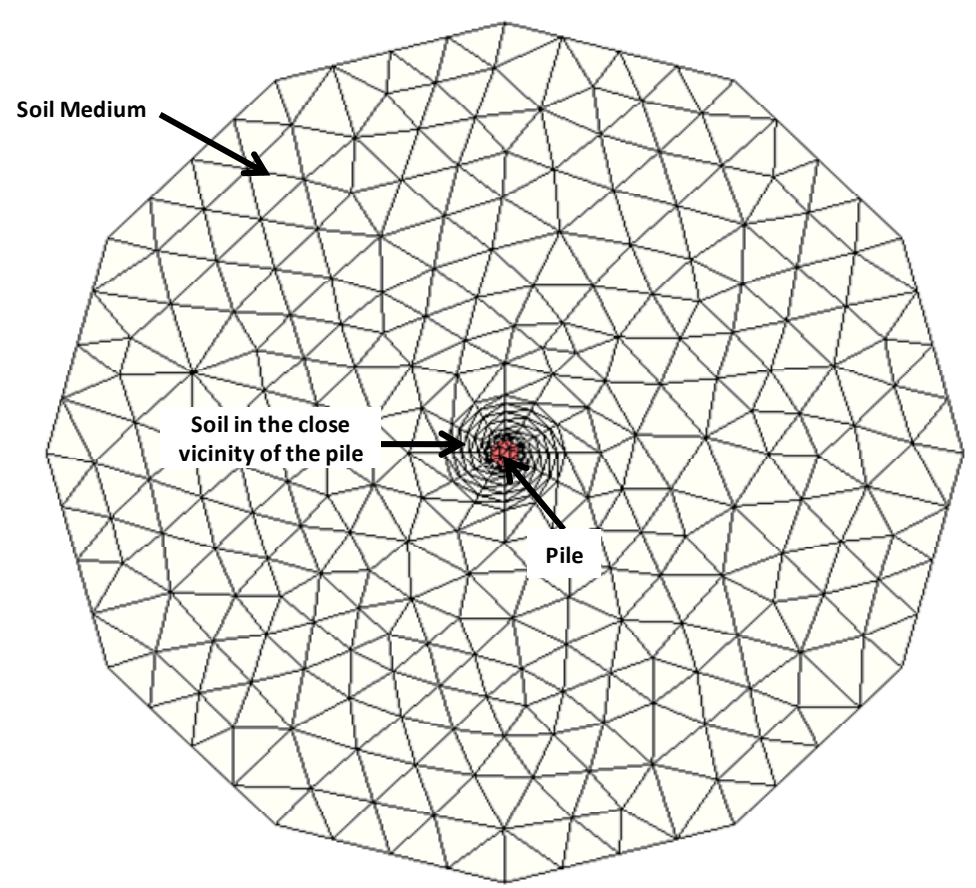

Fig. 12 Cross section of the finite element mesh on the ground surface

defined by a pair of nodes, and although as shown in Fig. 11 seems having a certain thickness, in the calculation the coordinates of each node pair are identical; thus the element has zero thickness. The advantages of the pair of nodes are to allow the slipping and gapping when the differential displacement occurs. Shear strength of the interfaces was defined by Mohr-Coulomb failure criterion and the tensile strength of the interfaces are set to zero in order to allow gapping between the piles and the supporting soil in the pile foundation. The main interface parameter is the strength reduction factor $\left(R_{\text {inter }}\right)$, which is taken into account the strength and stiffness decrease of the interface element in the corresponding soil layer. The stiffness matrix for 3D wedge interface elements is obtained by means of Gaussian integration using the integration points. $R_{\text {inter }}$ serves to model the soil-structure interface by reducing the cohesion $(c)$, friction angle $(\phi)$ and shear modulus $(G)$ at the interface using the following relationships

$$
\begin{gathered}
c_{\text {inter }}=R_{\text {inter }} \times c_{\text {soil }} \\
\tan \left[\phi_{\text {inter }}\right]=R_{\text {inter }} \times \tan \left[\phi_{\text {soil }}\right] \leq \tan \left[\phi_{\text {soil }}\right] \\
G_{\text {inter }}=R_{\text {inter }}^{2} \times G_{\text {soil }} \\
\psi_{\text {inter }}=0 \quad \text { if } \quad R_{\text {inter }}<1 \quad \text { otherwise } \quad \psi_{\text {inter }}=\psi_{\text {soil }}
\end{gathered}
$$

where, $R_{\text {inter }}$ is the interface reduction factor $(<1), c_{\text {inter }}$ is the cohesion of the interface, $c_{\text {soil }}$ is the cohesion of the surrounding soil, $\phi_{\text {inter }}$ is the friction angle of the interface, $\phi_{\text {soil }}$ is the friction angle 
of the surrounding soil, $G_{\text {inter }}$ is the shear modulus of the interface, $G_{\text {soil }}$ is the shear modulus of the surrounding soil, $\psi_{\text {inter }}$ is the dilatancy angle of the interface, and $\psi_{\text {soil }}$ is the dilatancy angle of the surrounding soil. It should be noted that the 8 -node quadrilateral interface elements provide a second-order interpolation of displacements.

Due to uncertainties in defining the interface reduction factor, various cases, as presented in Table 3, are considered in this study to investigate the influence of $R_{\text {inter }}$ on the pile response. The values of baseline/original $R_{\text {int }}$ (Case A), reported in Table 3, were recommended by Kim and Jeong (2011) for Incheon Bridge site applicable to this study. For the parametric study, authors have considered $20 \%$ deviation from the baseline/original values. Three dimensional 15 -node

Table 3 The adopted range of the interface reduction factor in the numerical analysis

\begin{tabular}{cccc}
\hline \hline Material & \multicolumn{3}{c}{$R_{\text {inter }}$} \\
\cline { 2 - 4 } & Case A & Case B (+20\%) & Case C $(-20 \%)$ \\
\hline Upper clay 1 & 0.50 & 0.6 & 0.4 \\
Upper clay 2 & 0.50 & 0.6 & 0.4 \\
Lower clay 1 & 0.50 & 0.6 & 0.4 \\
Lower clay 2 & 0.50 & 0.6 & 0.4 \\
Silty clay & 0.65 & 0.78 & 0.52 \\
Residual soil & 0.70 & 0.84 & 0.56 \\
\hline
\end{tabular}

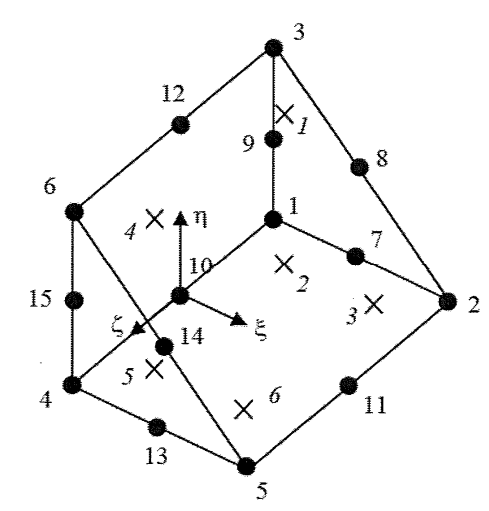

15-Node wedge element

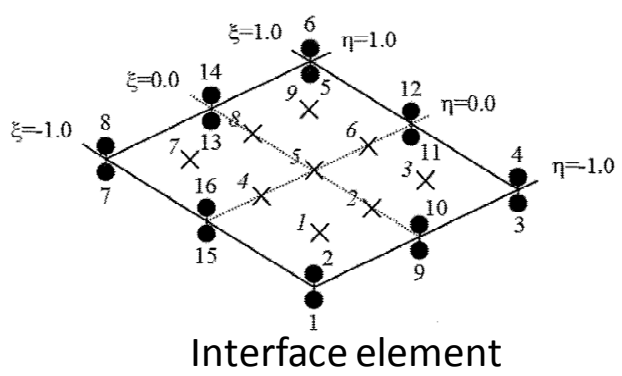

Fig. 13 The adopted 3D element in the numerical modelling

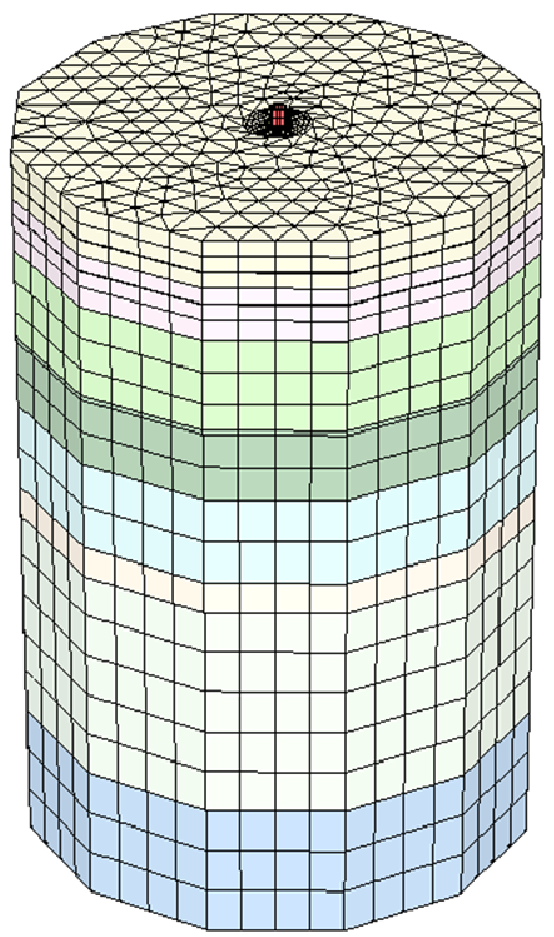

Fig. 14 The three-dimensional mesh used in the finite element model 
wedge elements composed of 6 node triangles in horizontal direction and 8-node quadrilaterals in vertical direction have been adopted for the numerical simulations of both soil and pile. It should be noted that the accuracy of the 15-node wedge element is comparable with the 6-node triangular elements in 2D analysis. The interface element is different from the 8-node quadrilateral that they have a pair of nodes with zero thickness instead of single node as illustrated in Fig. 13. In the generation of the three-dimensional mesh for the model, care was taken to achieve a satisfactorily fine mesh in the vertical ( $y$-axis) direction. Further refinement of the mesh towards the upper layers of the pile was carried out through the creation of additional work planes in those regions. The model comprised of 83350 nodes and 37310 elements. The resulting three-dimensional mesh used in the finite element model is shown in Fig. 14.

The modelling for this study required the definition of multiple calculation phases - to enable the calculation of initial stresses in the model and to calculate the response of the model to different lateral loads. To calculate the initial stresses present in the modelled soil-pile system (prior to any external loading), the $K_{0}$ procedure was chosen as the PLAXIS calculation method. The modelling of the pile installation is rather complicated, so the pile is assumed to be in a stress-free state at the beginning of the analysis, and the effect of the pile installation is ignored. Although there are several relationships to calculate the coefficient of earth pressure at rest, two approaches based on plasticity Index suitable for cohesive soils proposed by Massarsch (1979) and Lee and Jin (1979) have been adopted in this study. Tables 4 and 5 show the different cases used in this study to calculate $K_{0}$ values required to generate the initial stress field.

Table 4 Three cases of $K_{0}$ used in this parametric study

\begin{tabular}{cccc}
\hline \hline Reference & Normally consolidated soil & Over consolidated soil & Case \\
\hline Massarsch (1979) & $K_{0}^{n c}=0.44+0.42\left[\frac{\mathrm{PI}(\%)}{100}\right]$ & $K_{0}^{o c}=K_{0}^{n c} * \mathrm{OCR}^{0.5}$ & Case D \\
\hline Lee and Jin (1979) & $K_{0}^{n c}=0.24+0.31 \times \log \mathrm{PI}(\%)$ & $K_{0}^{o c}=K_{0}^{n c} * \mathrm{OCR}^{0.5}$ & Case E \\
\hline PLAXIS Default & $K_{0}=K_{0(N C)} \mathrm{OCR}^{0.5}-\frac{v_{u r}}{1-v_{u r}}(\mathrm{OCR}-1)+\frac{K_{0(N C)} \mathrm{POP}-\frac{v_{u r}}{1-v_{u r} \mathrm{POP}}}{\left|\sigma_{\mathrm{yy}}\right|}$ & Case F \\
\hline
\end{tabular}

*Note: $K_{0}^{n c}$ is the coefficient of lateral earth pressure at rest for the normally consolidated stress range, PI is the Plasticity Index, $v_{u r}$ is the Poisson's ratio, $\sigma_{y y}$ is the effective vertical stress, OCR is the over-consolidation ratio, and POP is the past-overburden pressure

Table 5 Three cases of $K_{0}$ used in this parametric study

\begin{tabular}{cccc}
\hline \hline \multirow{2}{*}{ Material } & \multicolumn{1}{c}{$K_{0}$} & Case F \\
\cline { 2 - 4 } & Case D & Case E & 1 \\
\hline Upper clay 1 & 0.680 & 0.840 & 1 \\
Upper clay 2 & 0.680 & 0.840 & 1 \\
Lower clay 1 & 0.706 & 0.868 & 1 \\
Lower clay 2 & 0.706 & 0.868 & 1 \\
Silty clay & 0.732 & 0.892 & 1 \\
\hline
\end{tabular}




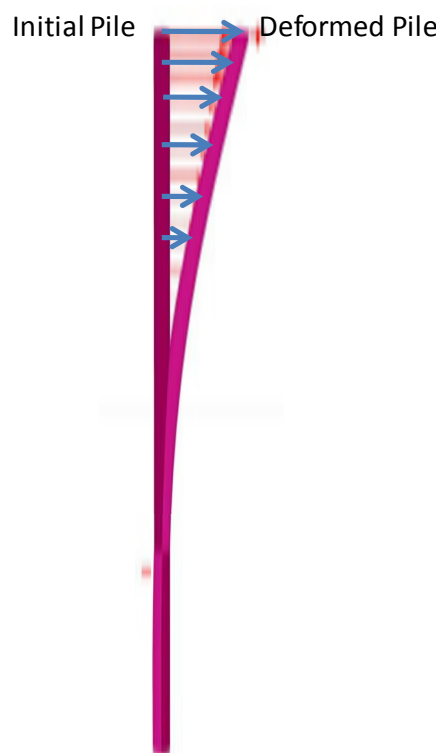

Fig. 15 Schematic diagram of pile deformation sjbjected to the lateral loading

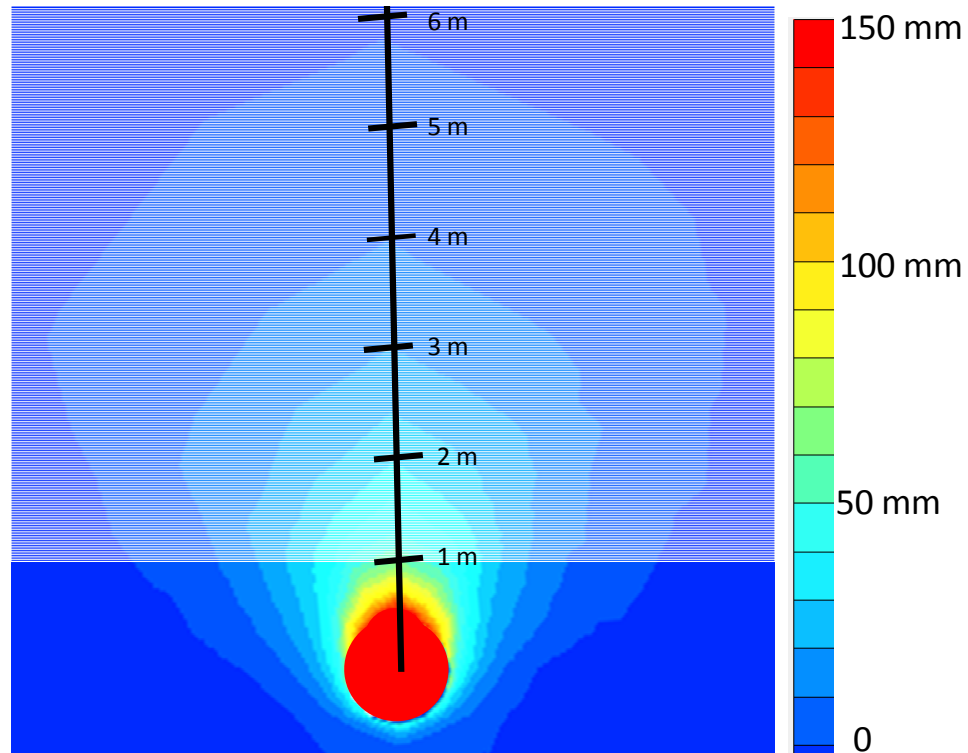

Fig. 16 Horizontal displacement of the ground surface in the vicinity of the pile subjected to $800 \mathrm{kN}$ load

Following the initial phase simulating the pile-soil system in equilibrium condition under gravity loading, there was the definition of eight additional phases. Each of these phases was defined so as to model different lateral loads to act on the pile. These loads are assumed to be in the order of those used in the lateral load tests for the Incheon Bridge case study. The calculation phase includes 8 stages capturing the associated lateral loading of $100 \mathrm{kN}$ to $800 \mathrm{kN}$ with an increment of $100 \mathrm{kN}$. Each load was represented as a horizontal, single component ( $x$-component) force.

\section{Results and discussion}

Fig. 15 illustrates the general deformed shape of the pile under lateral loading and as expected, the maximum lateral deformation of the pile occurs at its head. Fig. 16 shows the contours of the horizontal soil displacement in the vicinity of the pile in the direction of the applied external load. It can be concluded that the horizontal soil movement drop to $30 \%$ of the maximum displacement $(2 m$ or $2 d)$ away from the pile centre.

\subsection{Influence of the in-situ earth pressure coefficient $K_{0}$}

The influence of the in-situ earth pressure coefficient, $K_{0}$, on the response of laterally loaded pile has been specifically studied in this section. It should be noted that while investigating effects of $K_{0}$ on the performance of the laterally loaded pile, the baseline/original values of $R_{\text {int }}$ (Case $\mathrm{A}$ ) were adopted. Figs. 17(a)-(b) show the deflection of the pile under the applied loads of $200 \mathrm{kN}$ and 
$600 \mathrm{kN}$, respectively. As expected, the maximum displacement of the pile occurs at the pile head and degrades with depth. As shown, the numerical results are in a good agreement with the field measurements and the general trend of the lateral pile deformation can be closely predicted using the adopted finite element simulation procedure. It is evident that the variations of the coefficient of lateral earth pressure at rest $\left(K_{0}\right)$ in the specified range capturing the possible uncertainties, have a negligible effect on the horizontal displacement of the laterally loaded pile system.

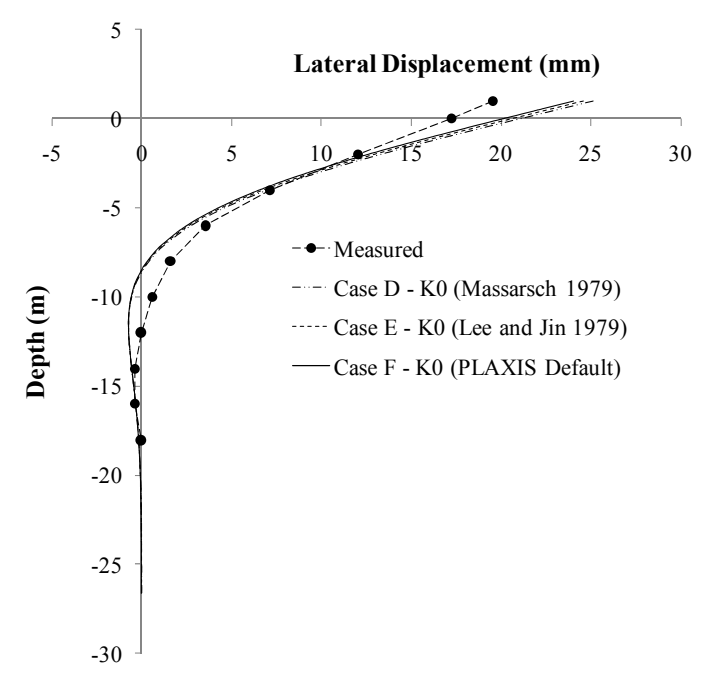

(a)

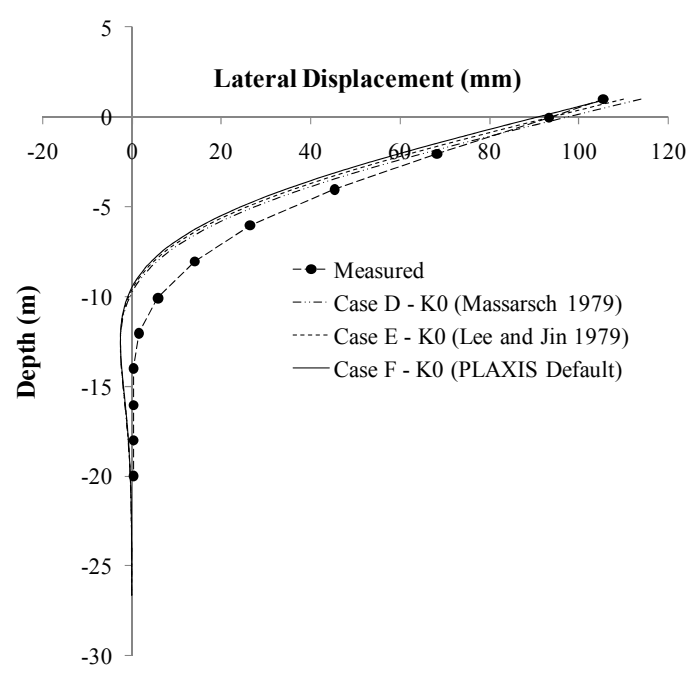

(b)

Fig. 17 Variation of depth - lateral displacement curves with $K_{0}$ : (a) for $200 \mathrm{kN}$ lateral load; and (b) for $600 \mathrm{kN}$ lateral load

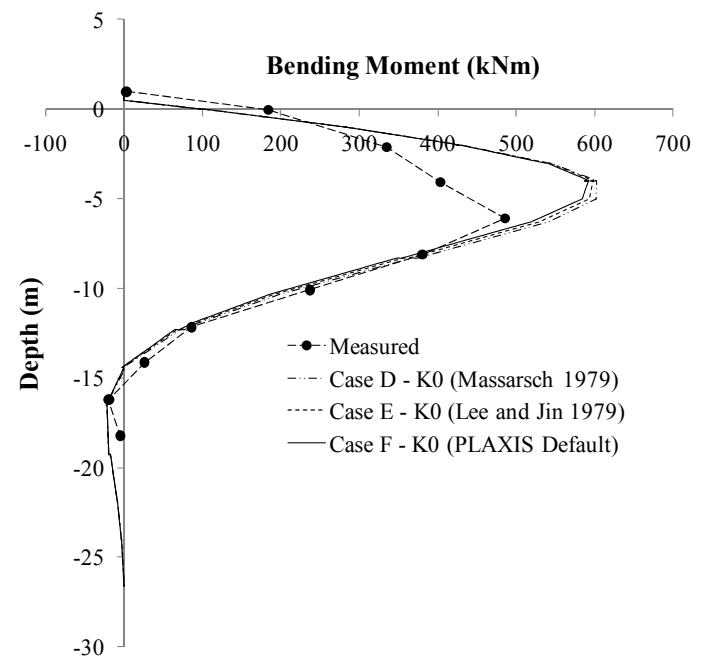

(a)

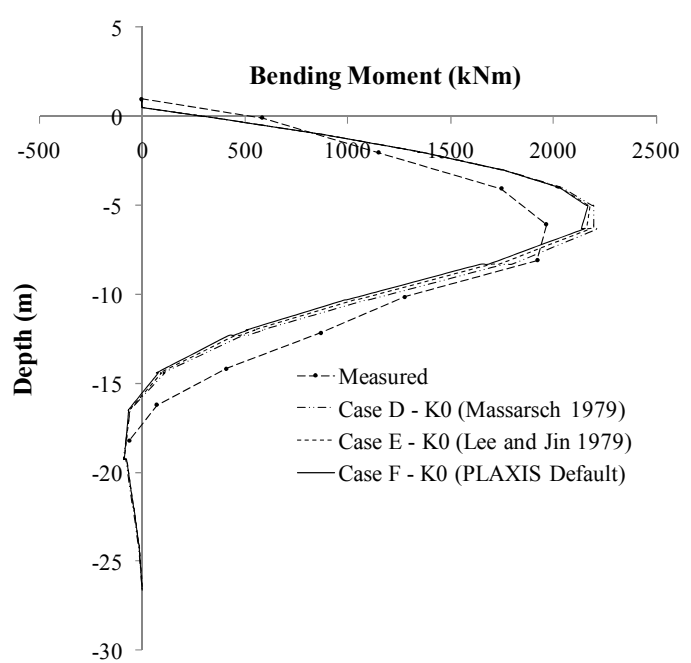

(b)

Fig. 18 Variation of depth - bending moment curves with $K_{0}$ : (a) for $200 \mathrm{kN}$ lateral load; and (b) for $600 \mathrm{kN}$ lateral load 
Figs. 18(a)-(b) indicate the variation of the bending moment generated in the pile with depth under the applied loads of $200 \mathrm{kN}$ and $600 \mathrm{kN}$, respectively. As expected, the maximum bending moment in the pile occurs below the ground surface. Although the numerical results over predict the maximum bending moment by approximately $20 \%$, the general trend of the bending moment is predicted reasonably well. There are only very slight differences in the profile of depth-bending moment with the variation of the lateral earth pressure coefficient at rest $\left(K_{0}\right)$. Thus, effect of uncertainties in $K_{0}$ can be ignored in the predictions of the maximum bending moment in the pile.

Figs. 19(a)-(b) show $p-y$ curves generated for the pile at depth of $2 D$ and $4 D$ below the ground surface, respectively. As expected, due to elasto-plastic behaviour of the soil, the relation between the total soil resistance in the pile cross section $(p)$ and lateral displacement of the pile $(y)$ is nonlinear. It should be noted that although clayey soils exhibit viscous behaviour (e.g., Le et al. 2012, Fatahi et al. 2013a). The predicted initial modulus of subgrade reaction, which is a function of elastic parameters of the soil, is in a good agreement with the field measurements, and $K_{0}$ will have very minor effects on the predicted values. However, the secant modulus of subgrade reaction increases as $K_{0}$ increases. The higher values of $K_{0}$ such as in Cases $\mathrm{E}$ and F, produces more isotropic stress field resulting in the lower values of displacement and larger values of modulus of subgrade reaction.

It appears that the uncertainties in estimation of $K_{0}$ have a negligible effect on the lateral load reaction of the pile system. This finding resonates with that found in Brown and Shie (1991) where changes in $K_{0}$ (using values of $K_{0}$ in the range of 0.5 to 1.5 ) appeared to have minor effect on the load transfer behaviour of a single pile system ( $p-y$ correlations). Additionally, Dodds and Martin (2007) found that the initial stress state has relatively little effect on large, laterally loaded pile groups. Consequently, there is less of a requirement to define $K_{0}$ values in a highly precise manner while investigating response of the pile to the lateral loads.

\subsection{Influence of the interface reduction factor $R_{\text {inter }}$}

In this section, the influence of the in-situ earth pressure coefficient $K_{0}$ on the response of laterally loaded pile has been specifically studied. It should be noted that while investigating effects of $R_{\text {int }}$ on the performance of the laterally loaded pile, default values reported in Tables 4 and 5 (Case F) were adopted. Figs. 20(a)-(b), 21(a)-(b), and 22(a)-(b) indicate depth-displacement, depth-bending moment and $p-y$ relationships, respectively. From careful investigation of the illustrated results, it can be concluded that the interface reduction factor $\left(R_{\text {inter }}\right)$ has a notable effect on the pile response under lateral loading. As shown in Figs. 20-22, although $R_{\text {inter }}$ slightly influences the predicted maximum pile bending moment, the initial modulus of subgrade reaction is considerably influenced by uncertainties in $R_{\text {inter }}$. Although the predictions adopting $3 D$ finite element solution are in good agreement with the field measurements, disparities in $p-y$ curves reported in Figs. 18 and 22 are more significant at shallower depth (i.e., 2D). This can be due to the fact that under the applied loading condition, the lateral displacement of the pile and consequently the soil are larger and thus soil approaches the yielding. In addition, under larger shear displacements, structure of the clayey soil may be degraded causing reduction in the ultimate strength in comparison to the peak shear strength, however possible cementation degradation and softening behaviour was not captured in this numerical modelling. Further information about cementation effects on the stress-strain behaviour of clayey soils can be found in Nguyen et al. (2014) and Fatahi et al. (2012, 2013b).

The significant influence of pile-soil interface friction and the $R_{\text {inter }}$ parameter has been already 


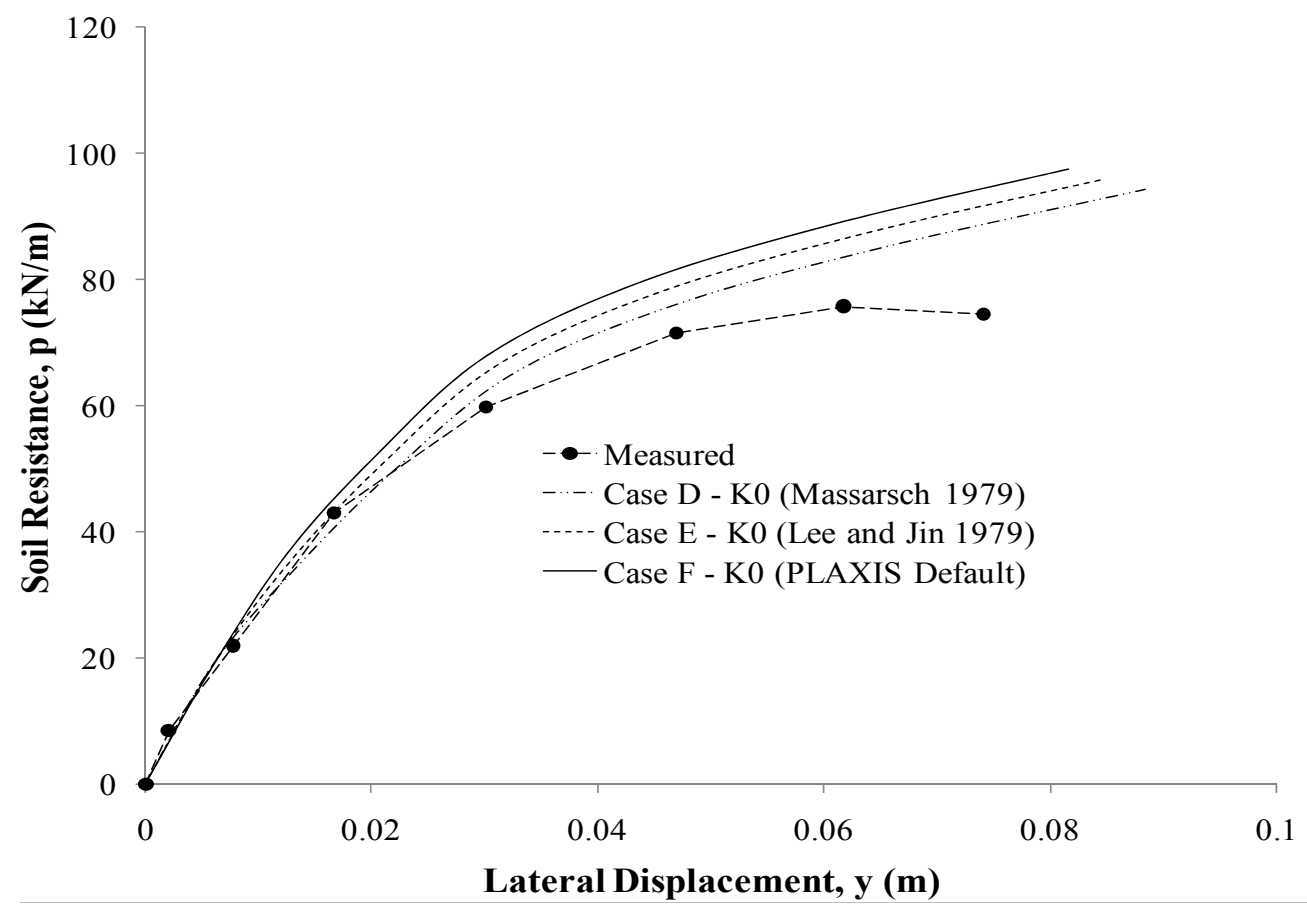

(a)

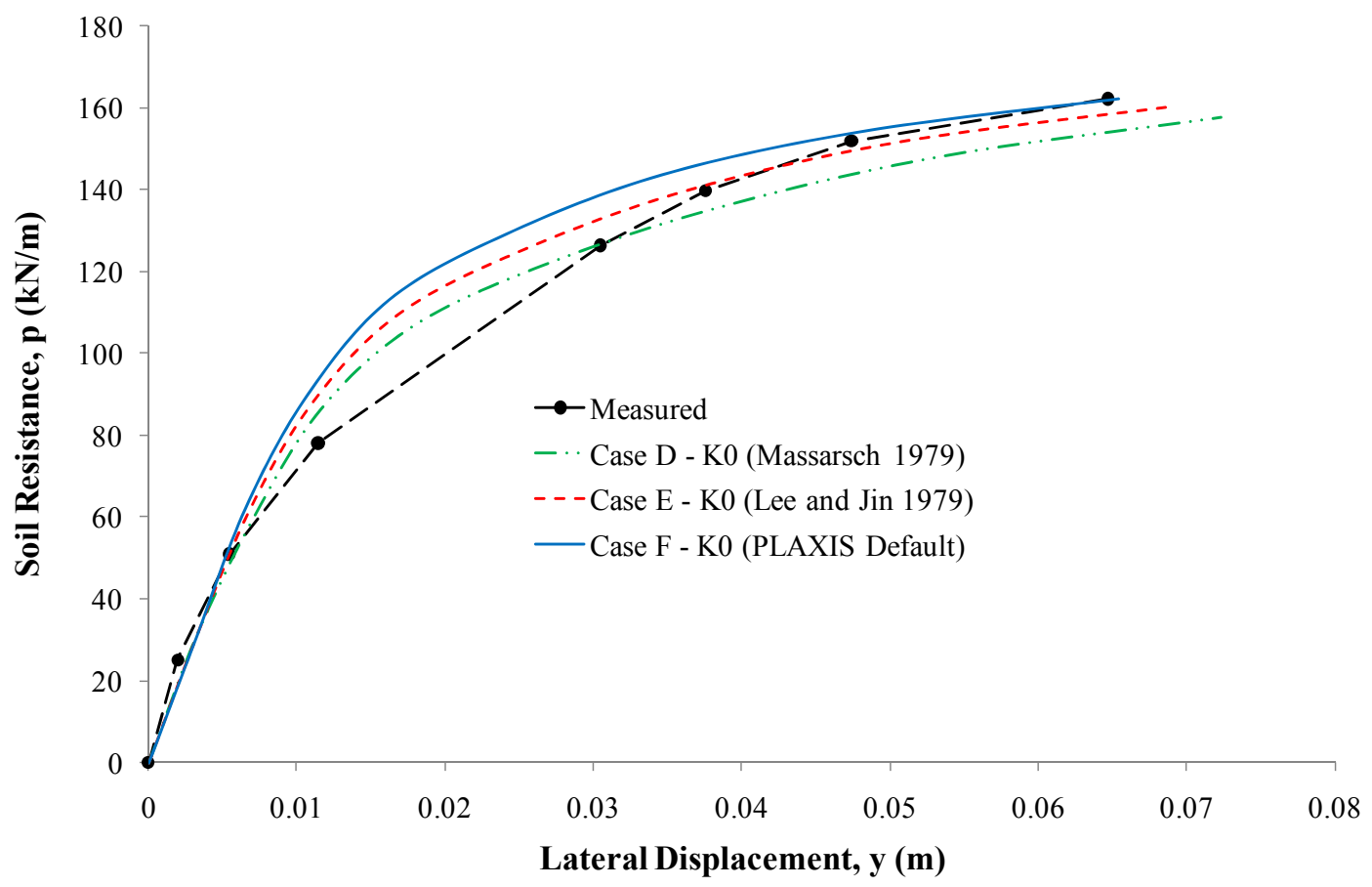

(b)

Fig. 19 Variation of $p-y$ curves with $K_{0}$ : (a) at $2 D$ depth; and (b) at $4 D$ depth ( $D=$ pile diameter) 


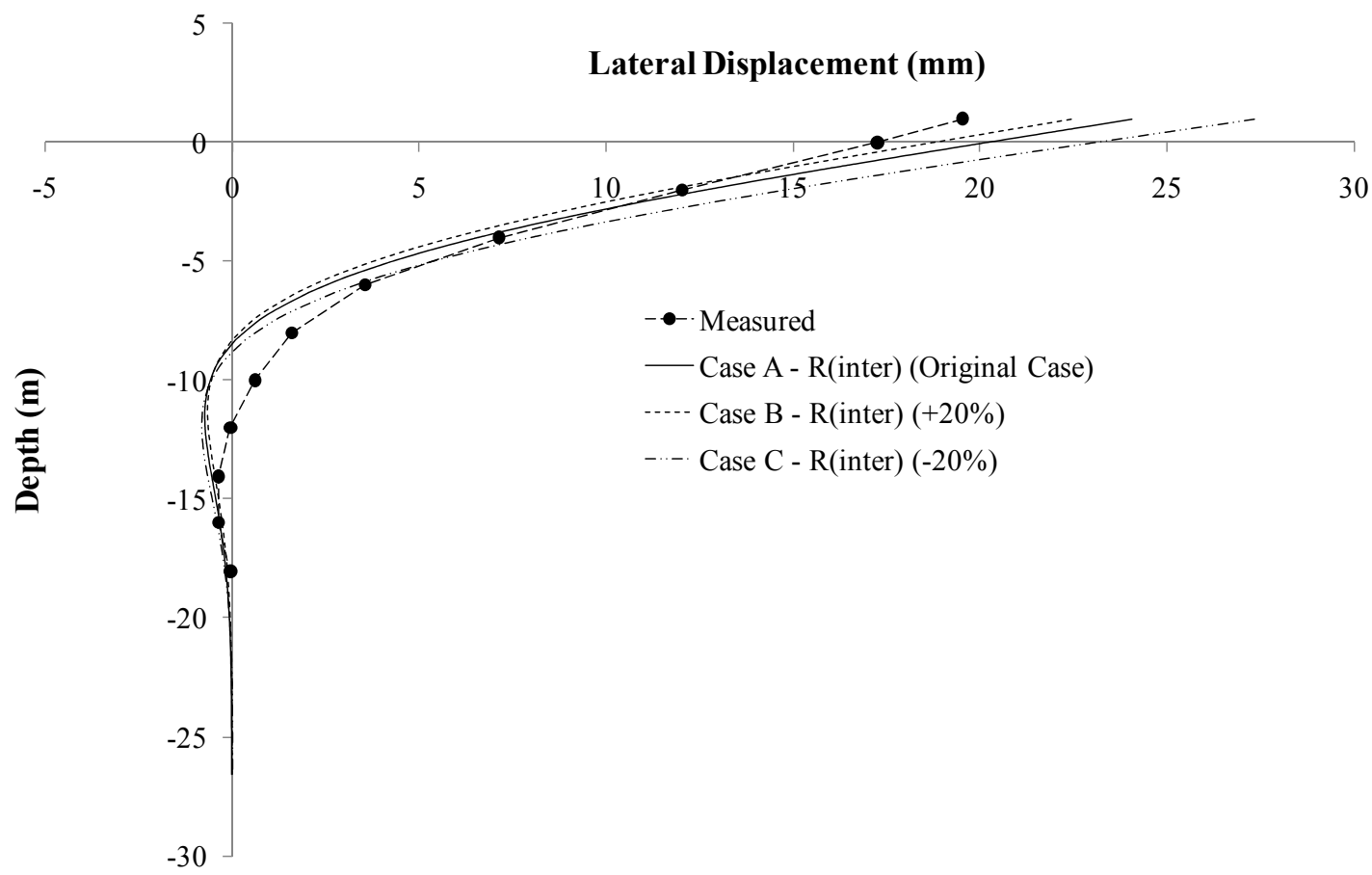

(a)

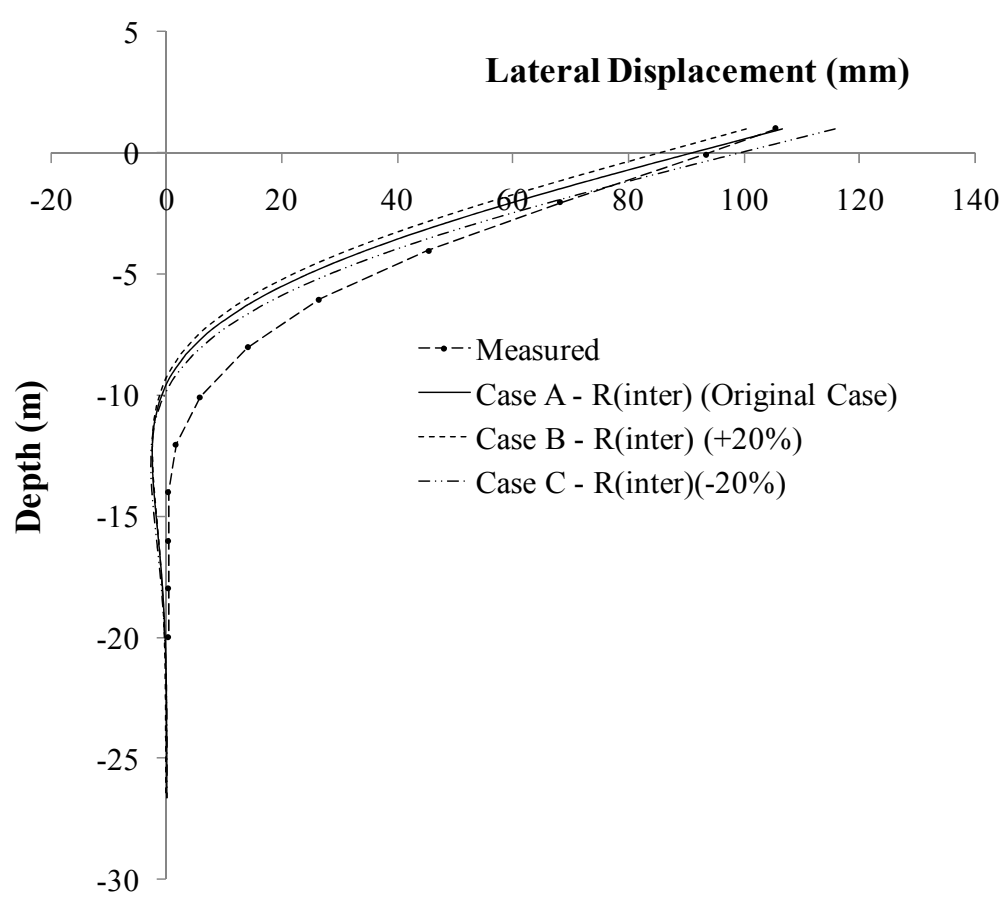

(b)

Fig. 20 Variation of depth - lateral displacement curves with $R_{\text {inter }}$ : (a) for $200 \mathrm{kN}$ lateral load; and (b) for $600 \mathrm{kN}$ lateral load 


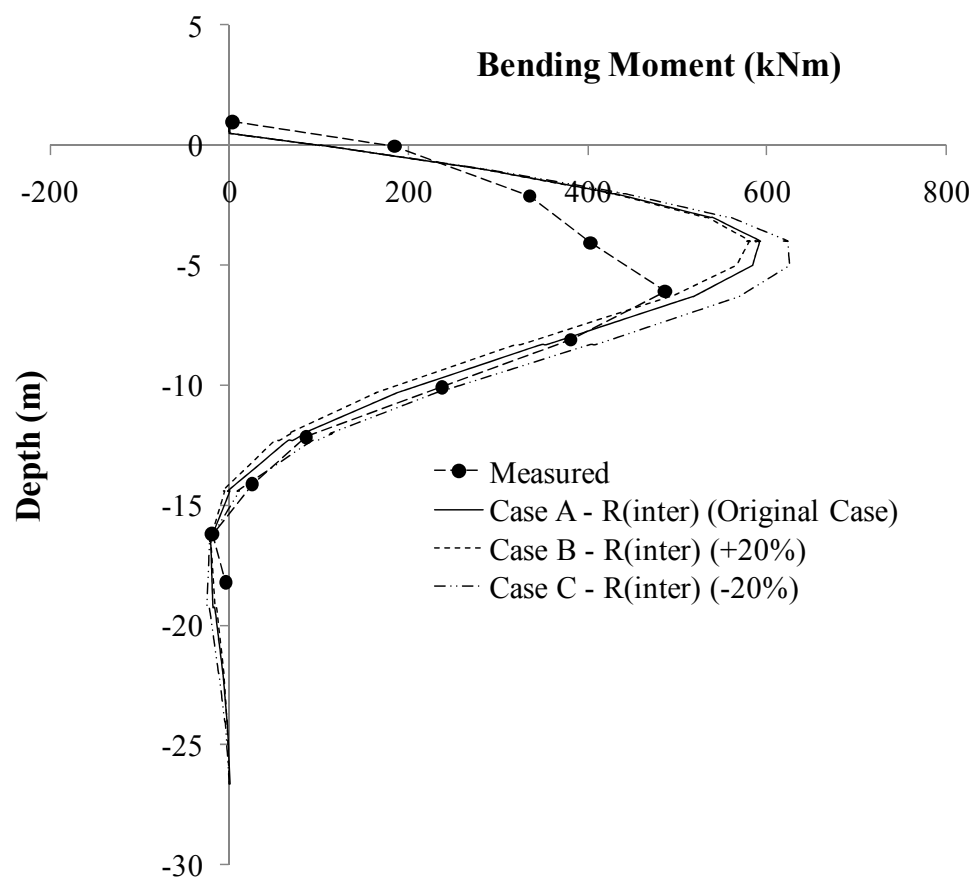

(a)

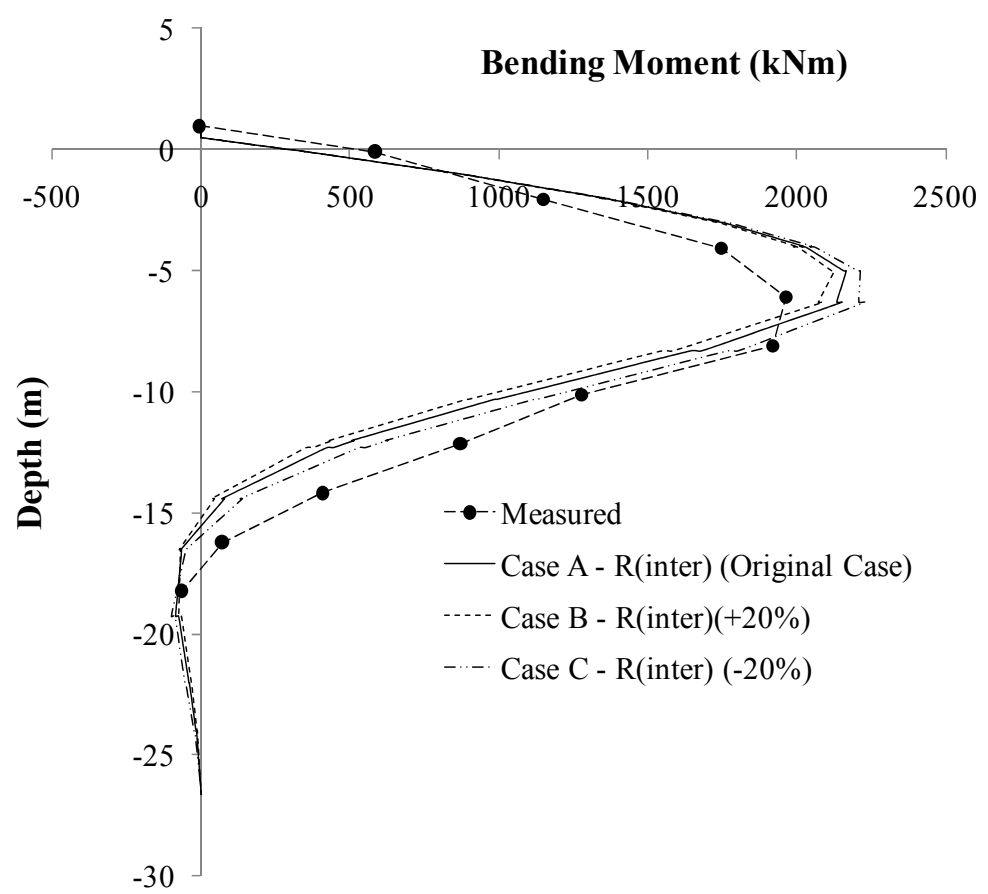

(b)

Fig. 21 Variation of depth - bending moment curves with $R_{\text {inter }}$ : (a) $200 \mathrm{kN}$ lateral load; and (b) for $600 \mathrm{kN}$ lateral load 


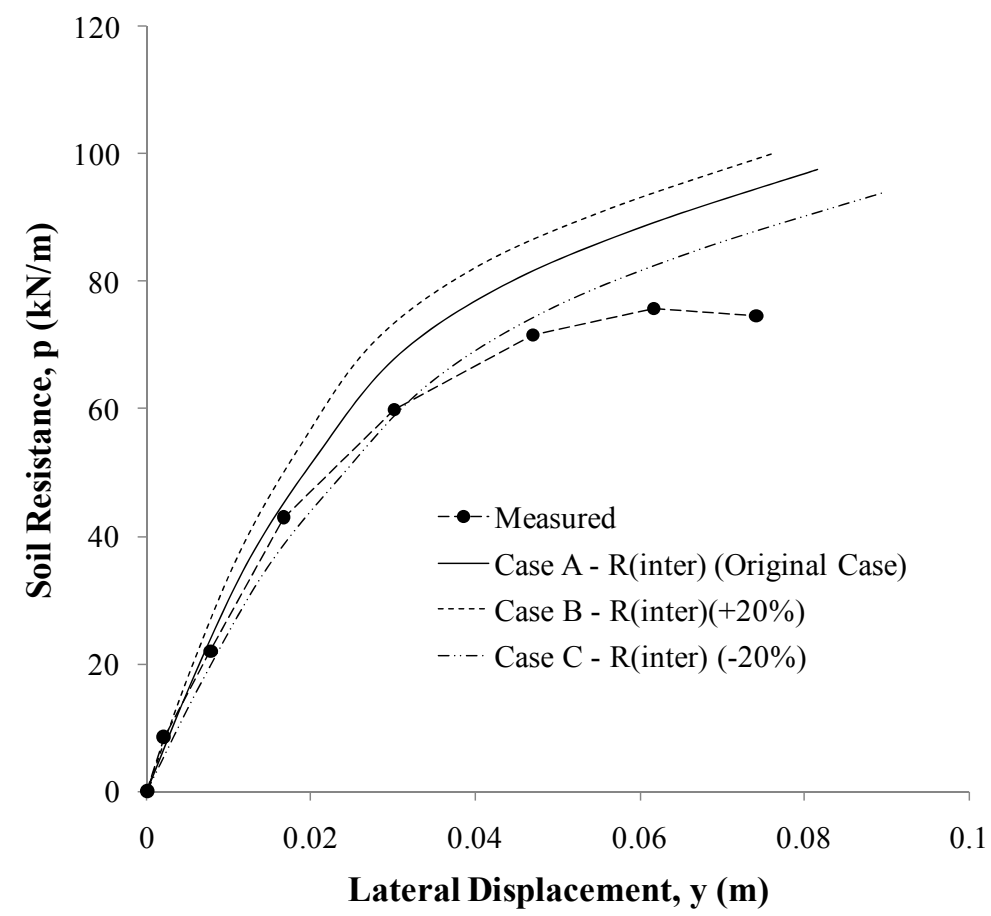

(a)

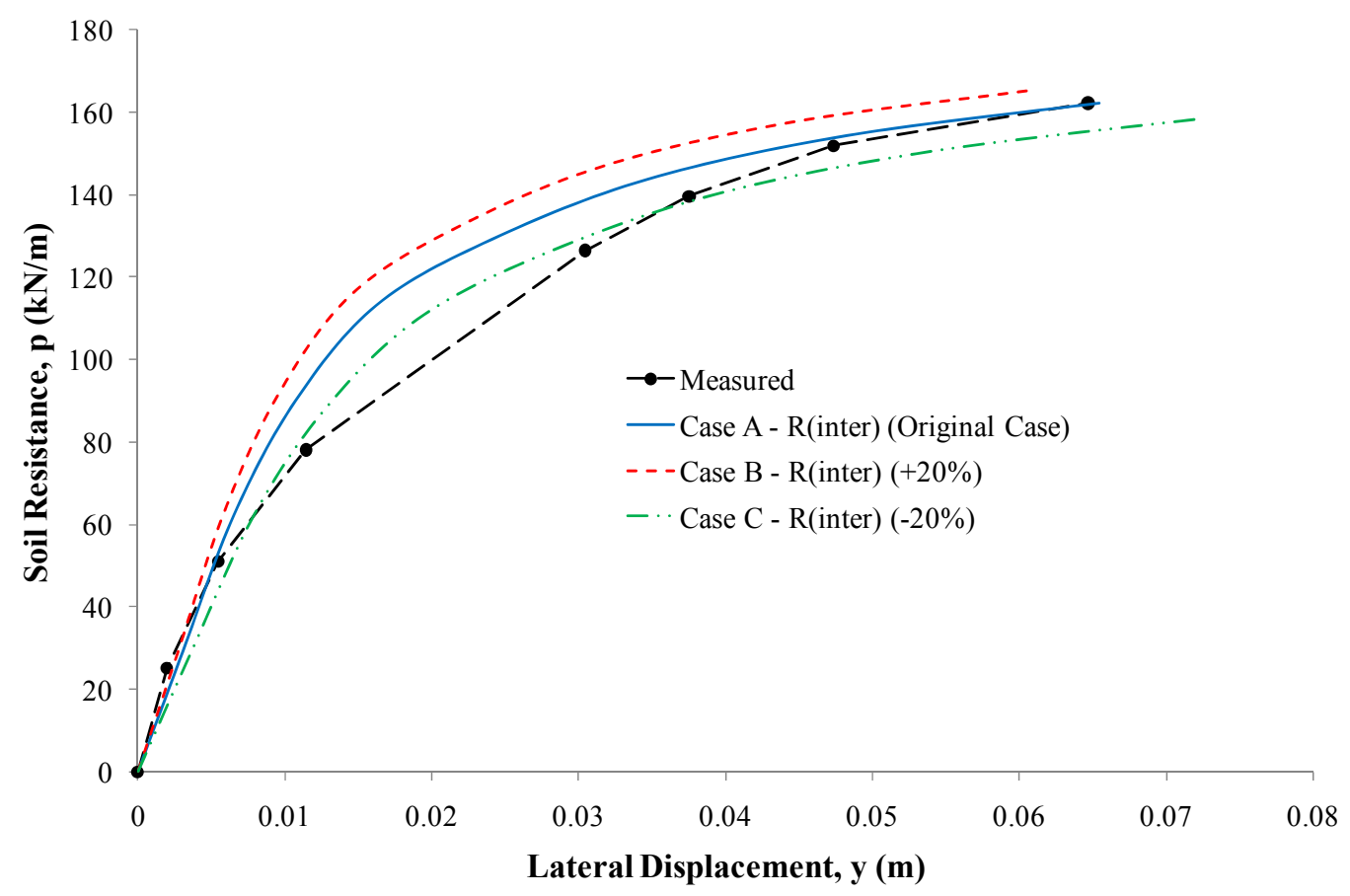

(b)

Fig. 22 Variation of $p-y$ curves with $R_{\text {inter }}$ at: (a) $2 D$ depth; and (b) $4 D$ depth ( $D=$ pile diameter) 
observed by Lebeau (2008), where small deviations in $R_{\text {inter }}$ resulted in increasingly and disproportionately large changes in the vertical settlement of a pile subjected to a vertical load. In addition, although the numerical investigations by Brown and Shie (1991) on laterally loaded piles concluded that it is important to specify a value for a pile-soil friction coefficient, the predictions were not particularly sensitive to the interface friction angle, so long as some frictional resistance is included. They reported that a perfectly frictionless interface resulted in a significant reduction in the lateral bearing capacity of the pile. It should be mentioned that they adopted frictional interface by introducing friction angle only (without any adhesion) and the interface resistance is very much dependent on the lateral earth pressure. However, in the current study, the total stress approach using the soil undrained shear strength, has been adopted and thus the lateral earth pressure would not influence the strength and stiffness of the interface elements. Results of this study indicates that adequate care should be taken in the selection of the pile-soil interface parameters, resulting in more accurate model predictions such as $p-y$ curves.

\section{Conclusions}

In design of piles to sustain horizontal or lateral loads several factors should be considered. This paper presents a comprehensive study on the assessment of soil properties, initial stress field and soil-pile interface characteristics on the overall performance of laterally loaded piles. Initially, a laboratory model test on single fixed headed pile in homogenous soft clay and medium dense sand beds have been performed followed by a numerical simulation with a simplified boundary element method. Since the developed BEM analysis ignores the possible shear stress likely to be developed at the interface, and is unable to capture the behaviour of laterally loaded pile in some complex field conditions, where the piles are often embedded in multi-layer subsoil and socketted at its tip, a rigorous finite element analysis has been carried out as well.

The results of this study indicates that for soft clay, the application of lateral loading on piles produces soil heave, pile-soil separation and tension cracks in the vicinity of ground surface adjacent to the interface, whereas in case of loose sand, a semi-elliptical zone of depression is formed at the back of the piles and soil heave at its front. The boundary element method (BEM) simulated results are found to be sensitive to the Young's modulus of soil. As visualised from the computed results, the lateral soil pressure was observed to be positive (i.e., acting opposite to the direction of applied lateral load) and negative near the pile toe, possibly because of reverse displacement. The bending moment attains a maximum negative value at the pile head due to rotational restraint and gradually increases in a curvilinear manner with increasing depth. After passing through the point of contra-flexure, the bending moment attains a maximum positive value and thereafter decreases with depth to zero at the pile base. These observations are essentially valid only for piles under normal working loads and not in the proximity of yield loads.

Three-dimensional nonlinear finite element analysis adopting PLAXIS 3D (version 2) has been employed to simulate the performance of a steel test pile constructed in Incheon Bridge site. The model predictions in terms of the pile deflection, the bending moment and $p-y$ curves along the length of the pile are in a good agreement with the field measurements. Furthermore, the finite element model was tweaked to carry out a numerical parametric analysis to investigate the effect of the initial stress state and interface parameters on behaviour of the laterally loaded pile system. The numerical results indicate that the coefficient of lateral earth pressure had a negligible effect on the depth-lateral displacement, depth-bending moment and $p-y$ curves of the pile in marine clay. 
The predicted initial modulus of subgrade reaction, which is a function of elastic parameters of the soil, is in a good agreement with the field measurements, and $K_{0}$ will have very minor effects on the predicted values. However, the secant modulus of subgrade reaction increases as $K_{0}$ increases. The higher values of $K_{0}$ produce more isotropic stress field resulting in the lower values of displacement and larger values of modulus of subgrade reaction. In addition, it is concluded that the interface strength reduction factor has a notable effect on performance predictions of the pile-system subjected to the lateral loading. Results of this study indicate that adequate care must be taken in the selection of the pile-soil interface parameters, resulting in more accurate model predictions such as $p-y$ curves. The results of this study can be used by practicing geotechnical engineers and researchers to better understand the significance of such parameters on finiteelement-based, laterally-loaded pile models. In turn, more accurate finite-element models can be created and utilised to assist in pile design and foundation engineering.

\section{Acknowledgments}

Authors would like to appreciate the financial support provided by UTS-ECR Grant to conduct the numerical analysis. In addition, the laboratory based model study was financially supported by the University Grants Commission, Government of India.

\section{References}

Ahmadi, M.M. and Ahmari, S. (2009), "Finite-element modelling of laterally loaded piles in clay", Proceedings of the ICE - Geotechnical Engineering, 162(3), 151-163.

Al-Douri, R. and Poulos, H.G. (1995), "Predicted and observed cyclic performance of piles in calcereous sand", J. Geotech. Eng., 121(1), 1-16.

Al-Mhaidib, A.I. (2006a), "Influence of loading rate on axial capacity of pile groups in clay from laboratory model tests", Proceedings of the 10th Arab Structural Engineering Conference, Kuwait, November, pp. 611-620.

Al-Mhaidib, A.I. (2006b), "Influence of shearing rate on interfacial friction between sand and steel", Eng. J., University of Qatar, 19, 1-16.

Al-Mhaidib, A.I. (2007), "Efficiency of pile groups in clay under different loading rates", Proceedings of the 17th International Offshore and Polar Engineering Conference, Lisbon, Portugal, July, pp. 1458-1463.

Allotey, N. and El Naggar, M.H. (2008), "A numerical study into lateral cyclic nonlinear soil-pile response", Can. Geotech. J., 45(9), 1268-1281.

Ashour, M. and Norris, G. (2003), "Lateral loaded pile response in liquefiable soil", J. Geotech. Geoenviron. Eng., 129(5), 404-414.

Basack, S. (2009), “A technical note on development and performance study of a set-up for imparting lateral cyclic load on piles", Mar. Georesour. Geotech., 27(4), 322-341.

Basack, S. (2010), "Response of vertical pile group subjected to horizontal cyclic load in soft clay", Latin Am. J. Solid. Struct., 7(2), 91-103.

Basack, S. and Dey, S. (2012), "Influence of relative pile-soil stiffness and load eccentricity on single pile response in sand under lateral cyclic loading", Geotech. Geol. Eng., Int. J., 30(4), 737-751.

Basack, S. and Sen, S. (2014), "Numerical solution of single piles subjected to pure torsion", J. Geotech. Geoenviron. Eng., ASCE, 140(1), 74-90.

Broms, B.B. (1964a), "The lateral resistance of piles in cohesive soils", J. Soil Mech. Found. Div., ASCE, 90(SM3), 27-63.

Broms, B.B. (1964b), "The lateral resistance of piles in cohesionless soils", J. Soil Mech. Found. Div., ASCE, 
90(SM2), 123-156.

Brown, D.A. and Shie, C.-F. (1991), "Some numerical experiments with a three dimensional finite element model of a laterally loaded pile", Comput. Geotech., 12(1), 149-162.

Chan, C.L. and Low, B.K. (2009), "Reliability analysis of laterally loaded piles involving nonlinear soil and pile behavior", J. Geotech. Geoenviron. Eng., ASCE, 135(3), 431-443.

Chandrasekaran, S., Boominathan, A. and Dodagoudar, G.R. (2010), "Group interaction effects on laterally loaded piles in clay", J. Geotech. Geoenv. Eng., 136(4), 573-582.

Chore, H.S., Ingle, R.K. and Sawant, V.A. (2012), "Parametric study of laterally loaded pile groups using simplified F.E. models", Coupled Syst. Mech., Int. J., 1(1), 1-7.

Dodds, A.M. and Martin, G.R. (2007), "Modelling pile behaviour in large pile groups under lateral loading", Technical Report MCEER-07-0004, MCEER University at Buffalo, Buffalo, NY, USA.

Douglas, D.J. and Davis, E.H. (1964), "Movement of buried footing due to moment and horizontal load and movement of anchor plates", Geotechnique, 14(2), 115-132.

Duncan, J., Robinette, M. and Mokwa, R. (2005), "Analysis of laterally loaded pile groups with partial pile head fixity", In: Advances in Deep Foundation; Proceedings of Geo-Frontiers Congress 2005, Austin, TX, USA, January, pp. 1-16.

Dyson, G.J. (1999), "Lateral loading of piles in calcareous sediments", Ph.D. Thesis, Department of Civil and Resource Engineering, University of Western Australia, Perth, Australia.

Fan, C. and Long, J.H. (2005), "Assessment of existing methods for predicting soil response of laterally loaded piles in sand", Comput. Geotech., 32(4), 274-289.

Fatahi, B., Khabbaz, H. and Fatahi, B. (2012), "Mechanical characteristics of soft clay treated with fibre and cement", Geosynth. Int., 19(3), 252-262.

Fatahi, B., Le, T., Le, M. and Khabbaz, H. (2013a), "Soil creep effects on ground lateral deformation and pore water pressure under embankments", Geomech. Geoeng.: Int. J., 8(2), 107-124.

Fatahi, B., Fatahi, B., Le, T. and Khabbaz, H. (2013b), "Small-strain properties of soft clay treated with fibre and cement", Geosynth. Int., 20(4), 286-300.

Hajialilue-Bonab, M., Sojoudi, Y. and Puppala, A.J. (2011), "Soil deformation pattern around laterally loaded piles", Int. J. Phys. Model. Geotech., 11(3), 116-125.

Hajialilue-Bonab, M., Sojoudi, Y. and Puppala, A.J. (2013), "Study of strain wedge parameters for laterally loaded piles", Int. J. Geomech., 13(2), 143-152.

Higgins, W., Vasquez, C., Basu, D. and Griffiths, D.V. (2013), "Elastic solutions for laterally loaded piles", J. Geotech. Geoenviron. Eng., 139(7), 1096-1103.

Hokmabadi, A.S., Fakher, A. and Fatahi, B. (2012), "Full scale lateral behaviour of monopiles in granular marine soils", Mar. Struct., 29(1), 198-210.

Hokmabadi, A.S., Fatahi, B. and Samali, B. (2014a), "Assessment of soil-pile-structure interaction influencing seismic response of mid-rise buildings sitting on floating pile foundations", Comput. Geotech., 55(1), 172-186.

Hokmabadi, A.S., Fatahi, B. and Samali, B. (2014b), "Seismic response of mid-rise buildings on shallow and end-bearing pile foundations in soft soil", Soil. Found., 54(3), 345-363.

Jamiolkowski, M. and Garassino, A. (1977), "Soil modulus for laterally loaded piles", Proceedings of the 9th International Conference on Soil Mechanics Foundation Engineering, Tokyo, Japan, July, pp. 43-58.

Kim, Y. and Jeong, S. (2011), "Analysis of soil resistance on laterally loaded piles based in 3D soil-pile interaction", Comput. Geotech., 38, 248-257.

Kim, Y., Jeong, S. and Lee, S. (2011), "Wedge failure analysis of soil resistance on laterally loaded piles in clay", J. Geotech. Geoenviron. Eng., 137, 678-694.

Kim, Y., Jeong, S. and Won, J. (2009), "Effect of lateral rigidity of offshore piles using proposed $p-y$ curves in marine clay", Mar. Georesour. Geotech., 27, 53-77.

Le, T., Fatahi, B. and Khabbaz, H. (2012), "Viscous behaviour of soft clay and inducing factors", Geotech. Geol. Eng.: Int. J., 30(5), 1069-1083.

Lebeau, J.S. (2008), "FE-analysis of piled and piled raft foundations", Technical Report: Institute for Soil Mechanics and Foundation Engineering, Graz University of Technology, Austria. 
Lee, Y.N. and Jin, B.J. (1979), "Measurement and prediction of $K_{0}$ ", J. Korean Soc. Civil Eng., 27(2), 57-66.

Levy, N.H., Einav, I. and Randolph, M.F. (2007), "Effect of recent load history on laterally loaded piles in normally consolidated clay", Int. J. Geomech., 7(4), 277-286.

Li, Z., Haigh, S.K. and Bolton, M.D. (2010), "The response of pile groups under cyclic lateral loads", Int. J. Phys. Model. Geotech., 10(2), 47-57.

Massarsch, K.R. (1979), "Lateral earth pressure in normally consolidated clay", The 7th European Conference on Soil Mechanics and Foundation Engineering, Volume 2, Brighton, England, September, pp. 245-249.

Matlock, H. (1970), "Correlations for design of laterally loaded piles in soft clay", Proceedings of the Second Annual Offshore Technology Conference, Houston, TX, USA, April, pp. 577-594.

Meyerhof, G.G. (1959), "Compaction of sands and bearing capacity of cohesionless soils", J. Soil Mech. Found. Div., 85(SM6), 1-29.

Meyerhof, G.G. and Adams, J.L. (1968), "The ultimate uplift capacity of foundations", Can. Geotech. J., 5(4), 225-244.

Mindlin, R.D. (1936), "Force at a point in the interior of a semi-infinite solid", Physics, 7, 195-202.

Narasimha Rao, S. and Prasad, Y.V.S.N. (1993), "Uplift behaviour of pile anchors subjected to lateral cyclic loading”, J. Geotech. Eng., 119(4), 786-790.

Narasimha Rao, S., Prasad, Y.V.S.N. and Veeresh, C. (1993), "Behavior of embedded model screw anchors in soft clays", Geotechnique, 43(4), 604-614.

Nguyen, L., Fatahi, B. and Khabbaz, H. (2014), "A constitutive model for cemented clays capturing cementation degradation", Int. J. Plast., 56, 1-18.

Oveseen, N.K. (1979), “The scaling law relationship - Panel discussion”, Proceedings of the 7th European Conference on Soil Mechanics and Foundation Engineering, Brighton, UK, September, Volume 4, pp. 319-323.

PLAXIS (2007), PLAXIS 3D Foundation Version 2, PLAXIS bv, The Netherlands.

Poulos, H.G. (1971a), "Behavior of laterally loaded piles: I — Pile groups", J. Soil Mech. Found. Div. 97(SM-5), 711-731.

Poulos, H.G. (1971b), "Behavior of laterally loaded Piles: II — Single piles", J. Soil Mech. Found. Div., 97(SM-5), 733-751.

Poulos, H.G. (1973), "Load deflection prediction for laterally loaded piles", Australian Geomech., G3(1), $1-8$.

Poulos, H.G. (1988), Marine Geotechnics, Unwin Hyman, London, UK.

Poulos, H.G. and Davis, E.H. (1980), Pile Foundation Analysis and Design, John Wiley \& Sons, New York, USA.

Reese, L.C. (1977), “Laterally loaded piles: Program documentation”, J. Geotech. Eng. Div., 103(4), 287305.

Reese, L.C. and Van Impe, W.F. (2011), Single Piles and Pile Groups under Lateral Loading, 2nd Edition, Taylor \& Francis Group, London, UK.

Reese, L.C., Cox, W.R. and Koop, F.D. (1975), "Field testing and analysis of laterally loaded piles in stiff clay", Proceedings of the Seventh Annual Offshore Technology Conference, Houston, TX, USA, May, pp. 671-675.

Robinsky E.I. and Morrison C.F. (1964), "Sand displacement and compaction around model friction piles", Can. Geotech. J., 1(2), 81-93.

Sawant, V.A. and Shukla, S.K. (2012), "Finite element analysis for Laterally loaded Piles in sloping ground", Coupled Syst. Mech., Int. J., 1(1), 59-78.

Som, N. (1993), "Behaviour of foundations on soft clay reinforced with timber piles", Final Technical Report, CSIR Project, No. 22 (203)/87-EMR II, Department of Civil Engineering, Jadavpur University, Kolkata, India.

Schofield, A.N. (1980), "Cambridge University geotechnical centrifuge operation: Rankine lecture". Geotechnique, 30(3), 227-268.

Tabatabaiefar, S.H.R., Fatahi, B. and Samali, B. (2013a), "Lateral seismic response of building frames 
considering dynamic soil-structure interaction effects", Struct. Eng. Mech., Int. J., 45(3), 311-321.

Tabatabaiefar, S.H.R., Fatahi, B. and Samali, B. (2013b), "Seismic behavior of building frames considering dynamic soil-structure interaction”, Int. J. Geomech., 13(4), 409-420.

Taylor, R.N. (1995), Centrifuges in Modelling: Principles and Scaling Effects, Geotechnical Centrifuge Technology, Blackie, London, UK, pp. 19-33.

Turner, J.P. and Kulhawy, F.H. (1987), "Experimental analysis of drilled foundations subjected to repeated axial loads under drained conditions", Report EL-5325, Electric Power Research Institute, Palo Alto, CA, USA.

Voottipruex, P., Suksawat, T., Bergado, D.T. and Jamsawang, P. (2011), "Numerical simulations and parametric study of SDCM and DCM piles under full scale axial and lateral loads", Comput. Geotech., 38(3), 318-329.

Yang, Z. and Jeremic, B. (2002), "Numerical analysis of pile behaviour under lateral loads in layered elastic-plastic soils", Int. J. Numer. Anal. Method. Geomech., 126(14), 1385-1406.

$C C$ 


\section{Nomenclature}

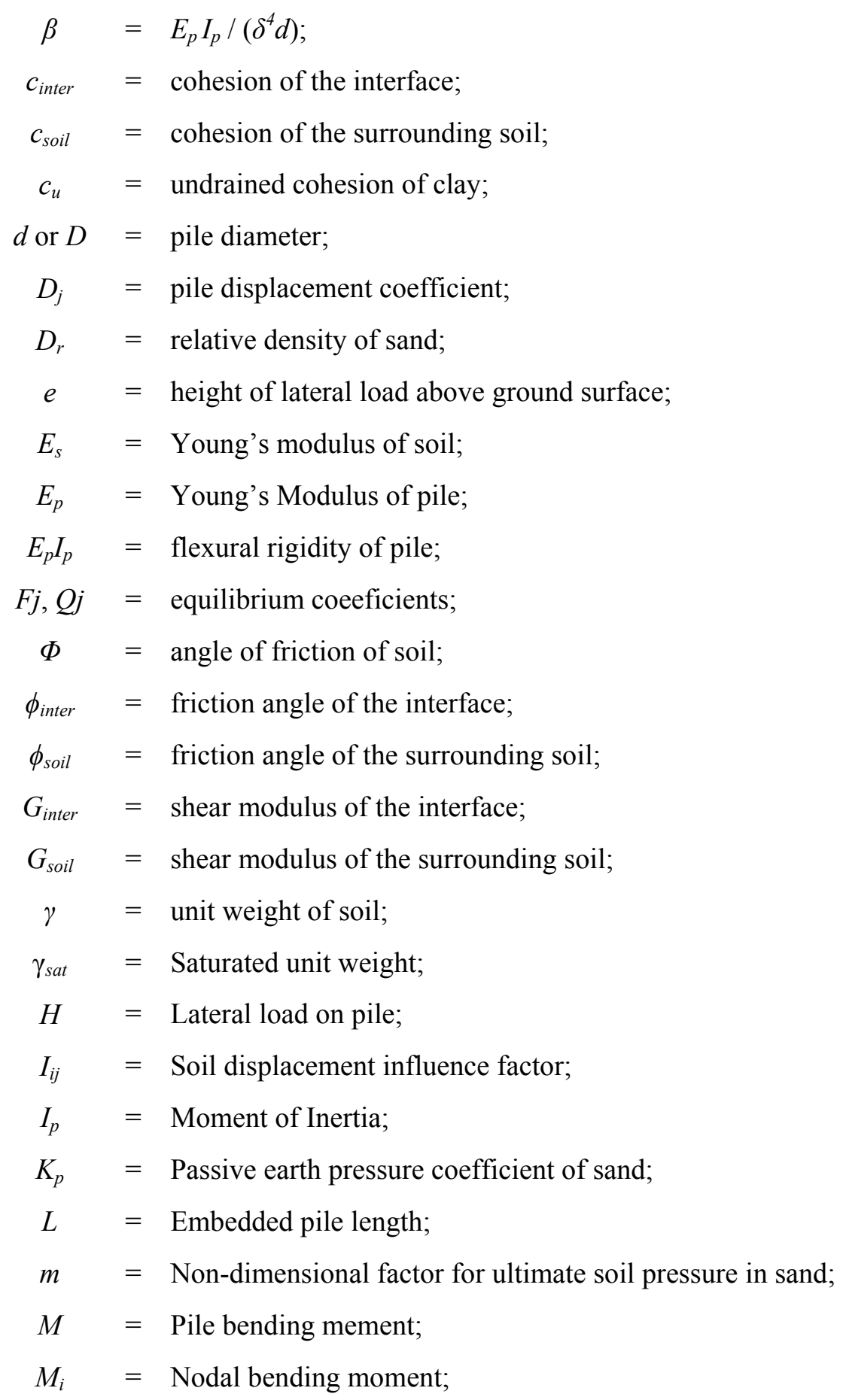




$$
\begin{aligned}
\mu_{s} & =\text { Poisson's ratio of soil; } \\
n & =\text { Number of pile elements; } \\
N & =\text { SPT value; } \\
v & =\text { Poisson's ratio; } \\
\omega & =2 \beta \delta /(2 e+\delta) \\
p & =\text { Lateral soil pressure on pile; } \\
p_{i} & =\text { Lateral soil pressure on the } i^{\text {th }} \text { pile element; } \\
\mathrm{PI} & =\text { Plasticity Index; } \\
r & =\text { radius to inner edge of the hollow pile; } \\
R & =\text { radius of the outer edge of the hollow pile; } \\
R_{\text {inter }} & =\text { interface reduction factor; } \\
\rho_{i} & =\text { nodal displacements; } \\
\psi_{\text {inter }} & =\text { dilatancy angle of the interface; } \\
\psi_{\text {soil }} & =\text { dilatancy angle of the surrounding soil; } \\
t & =\text { wall thickness of pipe piles; }
\end{aligned}
$$

